University of Zurich

Department of Economics

Working Paper Series

ISSN 1664-7041 (print)

ISSN 1664-705X (online)

Working Paper No. 349

\title{
The Psychological Effects of Poverty on Investments in Children's Human Capital
}

Guilherme Lichand, Eric Bettinger, Nina Cunha and Ricardo Madeira

Revised version, April 2021 


\title{
The Psychological Effects of Poverty on Investments in Children's Human Capital
}

\author{
By Guilherme Lichand, Eric Bettinger, Nina Cunha and \\ RiCARDO MADEIRA*
}

\begin{abstract}
Do poor parents respond inefficiently to future returns on investments, even when they would have the financial means to invest optimally? Combining multiple experiments, we document that when parents of high-school students in Brazil are offered the opportunity to invest in an educational program, (1) prior experience with the program closes the gap in willingness to invest between highand low-SES parents, but (2) financial worries reopen that gap. We show that financial worries lead parents to respond to small but immediate returns as if they were large, and to large but future returns as if they were small.
\end{abstract}

JEL: C93, D91, E24, I25, I26

Keywords: Psychology of poverty; Attention misallocation

This version: April 24, 2021

* Lichand: Department of Economics, University of Zurich (email: guilherme.lichand@econ.uzh.ch); Bettinger: Graduate School of Education, Stanford University (email: ebetting@stanford.edu); Cunha: FHI 360 (ncunha@fhi360.org); Madeira: Department of Economics, University of São Paulo (rmadeira@usp.br). We acknowledge helpful comments from Björn Bartling, Lorenzo Casaburi, Ernst Fehr, Anandi Mani, Michel Marechal, Frank Schilbach and Roberto Weber. Guilherme is a co-founder and chairman at Movva, the implementing partner of our survey experiment. Excellent research assistance by Akriti Dureja and Flavio Riva. All remaining errors are ours. 
Poverty creates salient financial needs that require immediate attention. Since attention is limited (Kahneman, 2011), poverty effectively reallocates it to present needs at the expense of consideration of future payoffs (Mullainathan and Shafir, 2013). Under certain conditions, such poverty-induced focus on the present has been shown to be excessive (e.g. Lichand and Mani, 2020), impairing the quality of decision-making and productivity among the poor (Kaur et al., 2021). In a striking example, access to credit - tempting because of its present benefits, while its costs are only in the future - can make the poor worse off than if credit were unavailable (Shah, Shafir and Mullainathan, 2015). Investments in children have the features of credit reversed: their costs are in the present, while their benefits are only in the future. As such, paying too much attention to present needs is likely to discourage poor parents from undertaking those investments, even when they yield high returns 1 This paper tests this hypothesis.

Studying this question outside the lab is challenging. Merely comparing how families of different socioeconomic status (SES) make investments in children would confound several other differences across high- and low-SES families, such as parents' knowledge about investment returns - a key determinant of human capital investments. To deal with this challenge, we resort to a lab-in-the-field experiment that randomly assigns financial worries within a sample of 2,223 caregivers of public high-school students in Brazil.

Concretely, we endow subjects with $\mathrm{R} \$ 10$ (about USD 3 in 2017, when the study took place) in airtime credit in exchange for answering an automated phone call. In that call, subjects are offered the opportunity to invest their endowment in signing up to an educational program that sends weekly text messages (SMS) with information about their child's school life, throughout the remainder of the school year. At the beginning of the call, we randomly assign subjects to financial worries by resorting to a survey experiment - a technique popular in cognitive psychology called priming, and increasingly used within Economics (e.g. Lichand and Mani, 2020, and Kaur et al. 2021, in the context of poverty's psychological effects) ${ }^{2}$ The idea is that the priming allows researchers to emulate (for a short period of time) the psychological effects of poverty that, in reality, capture poor subject's attention all the time. We prime parents by asking them what they would do if their child's school started charging a high amount for textbooks and uniforms ( $\mathrm{R} \$ 400$, about USD 130 and over $40 \%$ of the minimum wage at the time), and that amount were due by the end of that month. Textbooks and uniforms are typically provided at no cost for public school students in Brazil. Following previous studies (Mullainathan and Shafir, 2013), the control group is asked a variation of the same question, in which the only difference is that schools are said to charge a low amount instead ( $\$ 20$, about USD 6.50 at the time).

\footnotetext{
${ }^{1}$ It is not only the case that the poor under-invest in children on average, but also that children's characteristics associated with higher returns do not systematically predict investments; see Kremer and Glennerster (2011).

${ }^{2}$ See also Cohn et al. (2015), Gilad and Kliger (2008), Benjamin, Choi and Strickland (2010), Cohn, Fehr and Goette (2013), and Callen et al. (2014), in the context of influences on economic preferences.
} 
Manipulation checks within a few minutes of the priming confirm that it makes parents $15 \%$ more likely to worry significantly about coping with household bills. Consistent with the psychological mechanism that it is designed to capture, the effect of the priming is concentrated on low-SES parents: those are $32 \%$ more likely to state that they are desperate about household bills relative to primed high-SES parents.

Such experimental design features multiple advantages. First, we offer parents the opportunity to invest in the SMS program immediately after financial worries are made salient. This isolates the psychological effects of poverty on investment decisions, shutting down alternative mechanisms through which poverty presumably affects decision-making. ${ }^{3}$ Second, using airtime credit as endowment ensures liquidity constraints do not play a role. Since airtime is non-fungible (as, in Brazil, it cannot be transferred or used for making purchases), subjects' decision of whether to allocate it to the SMS program or not should be unaffected by potential effects that the priming could have on planned spending outside of the experiment. Third, we enforce parents' investment decisions without allowing for preference reversals in the future: parents' decisions are actually implemented at the end of the experiment, those who decide not to invest in the program have no future opportunity of doing so, and their endowment is converted into airtime credit - which they cannot transfer to the child or use to make other investments outside of the experiment. That ensures commitment problems do not play a role. As such, we can document the causal effects of financial worries among the poor on a real investment in children's human capital.

Documenting that those primed about financial worries invest differently than others does not necessarily point to inefficiency; after all, the control group might not invest optimally to start with. To deal with this challenge, we take advantage of the fact that all our subjects participated in a previous Randomized Control Trial (Bettinger et al. 2020) that evaluated the exact educational intervention we offer in the context of our survey experiment. Using machine learning techniques (Athey and Imbens, 2017), we can predict child-specific returns of investing on that educational program, and then control for predicted returns or restrict attention to the parents with the highest predicted returns - for whom it is much easier to claim that investing in the SMS program should be optima $]^{4}$ - when analyzing the psychological effects of poverty on investment decisions.

We start by documenting that high-SES parents (those with a college education) are much more likely to undertake the investment: in the control group of our experiments, $48.2 \%$ of high-SES parents invest in the SMS program, while only $31 \%$ of low-SES parents do so. Such gap is striking in the context of our experiment, since liquidity constraints do not play a role. Among the many potential reasons why low-SES parents might be less willing to invest relative to

\footnotetext{
${ }^{3}$ Examples include differential nutrition (Schofield 2014), noise (Dean, 2019) or lack of sleep (Bessone et al. 2020); see Schilbach, Schofield and Mullainathan (2016) for a comprehensive survey.

${ }^{4} \mathrm{At}$ the 75 th percentile of predicted returns, we estimate that the net present value of the investment is nearly 350 -fold that of the outside option; see Section I.C
} 
high-SES ones, we document that the latter are better able to anticipate the experience of receiving messages from the school than the former in the absence of prior experience with the program. In effect, being randomly assigned to the SMS program in the RCT over the previous school year nearly closes the SES investment gap.

Having said that, financial worries reopen $2 / 3$ of that gap. Results stand even upon restricting attention to parents with the highest predicted returns. Consistent with the psychological mechanism of interest, the priming has no effect on high-SES parents. This not only confirms the interpretation that priming captures poverty's psychological effects, but also rules out that the high fee entertained in the priming leads parents to trust schools to a lesser extent than those in the control group - what would decrease willingness to invest among all primed parents. We also find that financial worries do not significantly decrease investments among low-SES parents without prior experience with the program (whose willingness to invest was already low), ruling out that the priming leads poor parents to optimally cut down on other educational investments upon updating beliefs about the costs of school uniforms, in case they took the priming message literally.

We show that treatment effects are driven by attention misallocation. First, we document that primed parents respond significantly more to small but immediate returns. As part of the phone survey, we subject parents to audio versions of attention, working memory and impulse-control tests, following Lichand and Mani (2020). Those tests are incentivized: the $20 \%$ top-performers earn extra $\mathrm{R} \$ 2$ (about $0.70 \mathrm{USD}$ ), creating an opportunity for short-term rewards. In this type of tasks, it has been shown that subjects display excessive focus on present needs, particularly within the income range of our study participants (Lichand and Mani, 2020) 5 Consistent with previous findings, we document that subjects primed about financial worries perform significantly better in those tests (by about $1 / 3$ the effect of college education on cognitive performance). The effect is largely driven by low-SES families, consistent with the mechanism. Incidentally, this result rules out that effects are merely driven by poverty-induced present-bias Haushofer and Fehr (2014): in our cognitive tests, both effort and rewards are in the present.

Second, we document that the effects of financial worries on investment decisions are equivalent to those of responding to future returns as if they were small. We test this hypothesis by randomizing parents to information about child-specific returns of the SMS program, in advance of the survey experiment. Half of our subjects are informed via text message about the predicted effect of

\footnotetext{
5 Lichand and Mani (2020) documents that priming subjects to induce financial worries improves cognitive performance within short-term incentivized tasks at the per capita income levels of our study participants. Such global improvements in cognitive performance are also found by Kaur et al. (2021) and Shah, Mullainathan and Shafir (2019). This is in contrast to early experiments (Mullainathan and Shafir 2013 Mani et al. 2013) that document that subjects primed about poverty perform worse in cognitive tests.
} 
the program on their child's absences, two days before the phone survey. Because we predict that the program decreased only a few absences even when it significantly increased graduation rates, the informational intervention effectively framed returns as if they were small. As a result, it decreased parents' willingness to invest on average, and especially so among low-SES participants - an effect size statistically identical to that of financial worries.

We contribute to an active literature on the psychological consequences of poverty. While there is increasing evidence that poverty impairs executive functions, inducing individuals to focus on scarcity at hand at the expense of other dimensions (Mani et al., 2013; Haushofer and Fehr, 2014, Kaur et al., 2021; Lichand and Mani, 2020), this is the first paper to document its effects on human capital investments. Since educational achievement is directly consequential to future earnings, we show first-hand that the psychological effects of poverty can induce inefficient decisions with the potential to generate inter-temporal poverty traps.

Poverty-induced attention misallocation may shed light on the puzzling low take-up of preventive health care among the poor as soon as price is above zero, particularly among parents whose children would benefit the most from such investments Kremer and Glennerster (2011). Beyond investments in children, this mechanism might help rationalize the systematic misallocation of health investments in developing countries (such as Cohen, Dupas and Schaner, 2015, in the context of malaria testing and treatment, or Bai et al., 2017, in the context of demand for and usage of health insurance). More broadly, poverty-induced attention misallocation might also help understand why the poor often miss high-return investment opportunities (from inefficient usage of fertilizer to under-adoption of productive technologies), a central element to the agenda of behavioral development economics (Kremer, Rao and Schilbach, 2019).

\section{Background}

This section describes the educational context in which our experiment takes place in subsection I.A. followed by details about the SMS program parents have the opportunity to invest on in subsection I.B. Last, subsection I.C summarizes how we predict child-specific effects of the program and explains how such predictions map into returns on investment for each parent.

\section{A. Education in São Paulo State}

São Paulo is the wealthiest and most populous Brazilian State, and its educational system encompasses the largest number of students in the country. According to the 2017 Brazilian Educational Census, enrollment in the State amounted to over 1.8 million high-school students. Among those, 659,984 were junior students, $86 \%$ of which served by schools administered by the State. Despite being a relatively wealthy State - accruing to $40 \%$ of country's GDP -, São Paulo features high inequality in access to education: public schools tend to serve students 
from disadvantaged backgrounds. In our sample, which comprises a subset of parents of public school students in the State who took part in another study the year before (Bettinger et al., 2020), nearly 50\% earn less than 3 minimum wages (about 900 USD as of September, 2017), within the income range of slum dwellers in the State capital, and less than $12 \%$ are college educated. As such, public school students tend to perform particularly poorly: in 2017, São Paulo State's middle-school students enrolled in the public system scored 4.9 out of 10 in the National Index for the Development of Basic Education (Ideb) - which averages math and Portuguese standardized test scores, penalizing that average by grade repetition rates -, falling short of its already extremely modest target (5.0) for middle-school students in the State.

\section{B. The SMS program}

The educational program we offer parents in the context of our experiment (Eduq+, powered by the Brazilian EdTech Movva) delivers nudges via text messages (SMS) twice a week, directly to caregivers' cell phones. Inspired by READY4K! (York, Loeb and Doss, 2019), sequences start with a motivating fact, followed by a suggested activity (always non-curricular, as it is often the case that students' educational achievement is higher than that of their parents in Brazilian public schools); caregivers then receive an interactive message in the following week, posing them a question linked to the activity suggested the week before; last, a 'growth' message meant to highlight that following students' school life more closely should be routine concludes the sequence. Content is catered to students' age group. In the case of our study sample, messages cover the challenges of being a teenager and how caregivers can help navigate that difficult phase, the importance of studying hard and of finishing high school, and issues linked to career choice.

In the year prior to our study, Bettinger et al. (2020) documents through a Randomized Control Trial that the SMS program increases attendance by 3 percentage points in math classes (about 3 extra classes within 6 months), improves Math test scores by 0.09 standard deviation (as if treated students were about 1 extra quarter ahead in school), and increases middle-school graduation rates by 3 p.p. (decreasing the likelihood of grade repetition by roughly $1 / 3$ ). Such effects are documented for the same population as that of our study (see Section II.A.).

\section{Child-specific returns on investment}

We are ultimately interested in whether financial worries among the poor lead them to inefficiently invest in their children's human capital. This is, however, a challenging exercise: even if financial worries were randomly assigned, it is not obvious whether parents should optimally invest or not.6

\footnotetext{
${ }^{6}$ In an online experiment, Burlacu et al. (2019) document that financial worries induce poor parents to spend more on household necessities at the expense of investments in children, relative to the control
} 
To deal with that challenge, we take advantage of the prior RCT (Bettinger et al. 2020), which allows predicting the causal effect of the program for each of our study participants. With that, we can control flexibly for predicted returns when estimating the impacts of financial worries on investment decisions, and even restrict attention to those with the highest predicted returns - for whom it is much easier to argue that investing in the program should be optimal. 7

We predict heterogeneous treatment effects of the intervention evaluated in Bettinger et al. (2020) to generate an objective measure of returns on investment for each participant in our study. We focus on child-specific predicted impacts of the program on the probability of grade promotion, because of a direct link between educational achievement and future labor market returns. Following Athey and Imbens (2017), we computed child-specific returns through causal random forests (we present all details in Appendix B).

Higher educational attainment is associated with substantially higher future wages: in the 2017 Brazilian Household Survey (Pesquisa Nacional de Amostra de Domicílios, PNAD), the cross-sectional correlation between 1 additional year in school and monthly earnings is $\mathrm{R} \$ 135.76$ (about 45 USD at the time; Brazilian Institute for Geography and Statistics, 2017). Using that figure, we estimate that the expected present value of the investment would be 5 -fold that of the outside option even at the 25 th percentile of predicted returns, and nearly 350 -fold at the 75 th percentile 8

\section{Empirical strategy}

This section starts by describing our sample in subsection II.A, followed by details on the three experiments that we combine in subsection II.B. Next, subsection II.C describes the outcomes we analyze, and subsection II.D provides details on our estimation of treatment effects.

\section{A. Sample}

As our sampling frame, we resort to the participants' pool of our previous study (Bettinger et al. 2020), undertaken over the 2016 school year. We already had contact information for those parents, who had consented that we could reach out for additional surveys. Out of the nearly 20,000 subjects in Bettinger et al. (2020), we excluded those in pure control schools (because we anticipated that recall rates could be significantly lower within that sub-sample) and those in schools assigned to the nudge experiment (a sub-sample that was not balanced with respect to

group. Nevertheless, it could be that the latter inefficiently allocate their experimental budget to start with (e.g. due to time-inconsistent preferences or cognitive constraints), such that financial worries actually bring parents closer to optimality in the treatment group.

${ }^{7}$ That is the case because the net present value of the investment is extremely high, given the high labor market returns to educational achievement in Brazil (see Appendix B].

${ }^{8}$ See Appendix B 
student characteristics relative to the main study pool), what left us with 12,597 parents to re-contact in 2017.

Out of those, we successfully re-contacted 2,223 subjects. Appendix C compiles balance and selective non-response tests. Section II.B provides further details about the prior RCT assignment, and describes how we cross-randomized those study participants to our survey and information experiments.

\section{B. Experiment design}

We study the psychological effects of poverty on parents' willingness to invest in the educational program by combining a phone survey with three different experiments - as described in the subsections below. Table D1 in Appendix D showcases the sample distribution across all treatment cells.

\section{PHONE SURVEY}

To causally identify the psychological effects of poverty on parents' investment decision, we resort to a survey experiment. In that survey, conducted exactly one year after enrollment for the original experiment took place, we endow all 2,223 parents we are able to re-contact with $\mathrm{R} \$ 10$ (about USD 3, at the time) in exchange for answering a phone survey (interactive voice response unit, IVR). Over the course of that survey, subjects are offered the opportunity to invest this endowment in signing up for the same SMS program evaluated in Bettinger et al. (2020) 9 If a parent signed up for the program, text messages were effectively delivered throughout the third and fourth school quarters of 2017 10

\section{Previous RCT Assignment}

We explore exogenous variation in the extent to which participants had prior experience with the educational program over the previous school year by taking advantage of random assignment in Bettinger et al. (2020). In that study, undertaken over the two last school quarters of 2016, some parents of 9th-grade public school students were randomly assigned to weekly text messages from the school, while others received no weekly messages (the control group). Within those targeted by text messages, some were assigned to weekly information about their children's attendance, tardiness and homework completion, while others were assigned to salience messages that highlighted important dimensions of children's school life (but without child specific information). Since Bettinger et al. (2020) shows that child-specific information and salience messages had statistically identical impacts on educational outcomes relative to the pure control group, we pool

\footnotetext{
${ }^{9}$ See Appendix A for the full script of how the investment decision was framed.

${ }^{10}$ All parents who signed up in 2017 were targeted by messages meant to make their children's school life more salient, without child-specific information.
} 
both groups in the context of this paper 11 Manipulation checks at the end of the previous experiment confirm that parents assigned to the treatment group are much more likely to recall receiving text messages from the school $(89.8 \%$, versus $46.4 \%$ in the control group, a statistically significant difference at the $1 \%$ level). Taking advantage of experimental variation in prior experience with the program, we then analyze how it affects parents' willingness of investing in it.

\section{PRIMING FINANCIAL WORRIES}

At the beginning of the phone survey, we asked parents what they would do if their child's school started charging a high amount for textbooks and uniforms ( $\mathrm{R} \$ 400$, or about USD 130), and that amount were due at the end of that month. Brazilian public schools do not charge for textbooks or uniforms; the message was meant to trigger financial worries in face of unanticipated expenses. This priming technique, meant to make financial worries top-of-mind, attempts to emulate the psychological feeling of having financial worries constantly salient among the poor. Following previous studies (Mullainathan and Shafir, 2013), the control group is asked a variation of the same question, in which the only difference is that schools are said to charge a low amount instead $(\mathrm{R} \$ 20$, or about USD 6.50) ${ }^{12}$ The advantage of doing that is that all parents are primed to think about unanticipated expenses linked to their children' education; the only difference is that the magnitude of those expenses differ by a factor of 20. Assignment within the survey experiment was stratified by treatment assignment in the previous RCT. Taking advantage of experimental variation in financial worries, we then analyze how they affect parents' willingness to investing in the SMS program.

\section{INFORMING PARENTS ABOUT THE EFFECTS OF THE PROGRAM}

We cross-randomized parents to an intervention that disclosed the predicted effect of the SMS program on their child's absenteeism in math classes. Half of participants were informed over SMS about their child-specific predicted just two days prior the phone survey; the other half (the control group) received a neutral message, stating the number of families who had received messages from the program over the previous year. We used a much simpler algorithm to predict heterogeneous treatment effects on math attendance (causal trees instead of random forests; see Appendix B). We wanted to generate the simplest possible predictions that parents would still be able to successfully interpret. We rounded predicted treatment effects to the nearest integer, and informed parents that the program either did not decrease absences when predicted effects were nonpositive, or that it was expected to decrease 1, 2 or 3 absences over a period of 6

\footnotetext{
${ }^{11}$ The control group could still receive messages from the school, but at much lower frequency: schools could send up to 1 school-wide SMS per month, with communication about school activities. Less than $25 \%$ of schools ultimately did so.

${ }^{12}$ See Appendix $\mathrm{A}$ for the full script of treatment and control messages.
} 
months (see Appendix A for the exact framing of the treatment and control text messages).

Effect sizes are small even for students for whom the program's impacts on graduation rates are very large; as Bettinger et al. (2020) shows, the SMS intervention works through an array of additional mechanisms, including children's time use outside of school hours. Appendix D shows that child-specific predicted effects on attendance are not even informative about its effects on graduation rates (those are nearly zero correlated; Table D2.

Assignment within the information experiment was stratified by predicted treatment effects on math attendance and by treatment assignment in the previous RCT. Taking advantage of experimental variation in information about investment returns, we then analyze how it affects parents' willingness to investing in the SMS program.

\section{Data and outcomes}

Our key outcome of interest is parents' decision to invest in the SMS program or not. As part of the phone survey, we also elicit financial worries to document whether the priming indeed makes parents more likely to worry about household bills. Moreover, we also measure parents' cognitive performance in tests meant to capture their attention, working memory and impulse control, to provide evidence on the psychological mechanism underlying the effects of financial worries on investment decisions. Those additional outcomes are collected only after the investment decision has been elicited (see Appendix A for the complete script of the phone survey). The survey takes about 6 minutes in total.

We also have socio-demographic data on student and their primary caregivers' characteristics, from Bettinger et al. (2020)'s baseline survey. We use college education as a proxy of high socioeconomic status (SES). Appendix D shows that college education is 4-fold more likely within higher income brackets, with the advantage that while nearly $30 \%$ of subjects chose not to report income, we have information about caregivers' education for all subjects. Table D4 in Appendix $\mathrm{D}$ documents the correlation between willingness to invest and this proxy of high SES within the control group of our experiments (i.e. among parents without prior experience with the SMS program, not primed about financial worries, and not informed about the program's returns). High-SES parents are much more likely to undertake the investment: $48.2 \%$ of those invest in the SMS program, while only $31 \%$ of low-SES parents do so - a $35.7 \%$ SES investment gap (see Figure G1 in Appendix G).

\section{Estimation}

We estimate the following equation, using Ordinary Least Squares (OLS): 
(1) $Y_{i}=\alpha+\beta_{1}\left(\operatorname{Prior}_{i} \mathrm{x} \operatorname{Priming}_{i}\right)+\beta_{2} \operatorname{Priming}_{i}+\beta_{3} \operatorname{Prior}_{i}+\sum_{k} \gamma_{k} X_{k i}+\varepsilon_{i}$

In equation 1, $Y_{i}=1$ if parent $i$ invests in the SMS program, and 0 otherwise; Prior $_{i}=1$ if parent $i$ was randomly assigned to the SMS program in the previous $\mathrm{RCT}$, and 0 otherwise; Priming $i=1$ if parent $i$ is primed about financial worries, and 0 otherwise; $X_{i}$ is a vector of student and family characteristics; and $\varepsilon_{i}$ is an error term. We are interested in testing whether priming parents about financial worries decreases willingness to invest $\left(\beta_{1}, \beta_{2} \leq 0\right) 13$

At first, we restrict the analysis to the sub-sample of parents not informed about the returns of the program. In Section V.B, we estimate the full-interaction model to explicitly test whether the effects of the priming are statistically the same to those of information.

We also estimate effects separately by socioeconomic status to test the hypothesis that the psychological effects of financial worries are concentrated on low-SES parents. To do that, we split the sample according to whether parents are college educated or not. We estimate seemingly unrelated regressions (SUR) in order to test whether priming effects are statistically different across low- and high-SES parents.

Since treatment is assigned at the individual level within each experiment, we do not cluster standard errors.

\section{Effects of the priming on financial worries}

This section starts by discussing balance and selective non-response tests in subsection III.A. Next, subsection III.B presents manipulation tests to document that priming indeed makes financial worries top-of-mind.

\section{A. Balance and selective non-response tests}

Even though treatment conditions were randomly assigned across all subjects in the sampling frame, because take-up of the phone survey is low - only $11.2 \%$ of the universe picks up and answers the call through the end - it could be the case that the sample we end up with is selected with respect to one or more treatment conditions, or unbalanced with respect to students' or caregivers' characteristics. Appendix $\mathrm{C}$ documents that this is not the case: in our sample, treatment assignment is balanced within the prior RCT, the survey experiment, and the information experiment. Moreover, none of the interventions significantly predict response rates. This is the case even though $58.4 \%$ of our subjects have prior

\footnotetext{
${ }^{13}$ We do not estimate an instrumental variables model because worries are measured only coarsely in our phone survey - what would decrease the precision of our estimates without adding much to interpretability. Nonetheless, we use our survey measure to validate that the priming actually increases financial worries as intended.
} 
experience with the SMS program; the reason is that this figure approximately matches the share of treated subjects within Bettinger et al. (2020)'s sub-samples we target, once we combine the information and salience treatments. As such, we can attribute causal effects to any differences across treatment conditions in the context of our experiments.

\section{B. Financial worries}

We start by verifying whether the priming indeed increased financial worries as intended. We elicit financial worries categorically; subjects rate how worried they feel about not having enough money to pay all household bills at the end of the month ('not at all', 'somewhat worried', 'very worried' or 'desperate'; see Appendix A for the full script). Appendix $\mathrm{D}$ shows that, while $57.3 \%$ of subjects report to be very worried or desperate in the control group of our experiments (as most of our sample is indeed poor), those made to worry about unexpected and urgent school expenses are 8.3 percentage-point more likely to report being very worried or desperate about household bills due by the end of the month (significant at the $1 \%$ level). Consistent with the psychological mechanism, primed low-SES parents are over $45 \%$ more likely to state that they are desperate than primed high-SES ones ( $\mathrm{p}$-value of the difference=0.112).

\section{Effects of financial worries on investments in children}

Subsection IV.A turns to the the psychological effects of poverty on the investment decision, followed by robustness checks in subsection IV.B.

\section{A. Main results}

Table 1 estimates the effect of the priming on the probability of investing in the SMS program, following equation 1, restricting attention to the control group of the information experiment. Column (1) shows that prior experience with the program increases the likelihood of investment by 18 p.p. (from a $32.9 \%$ basis in the control group of our experiments), which corresponds almost exactly to the 17.2 p.p. SES investment gap (see Section II.C). Having said that, priming financial worries decreases investments by 10.8 p.p. among those parents (significant at the $10 \%$ level) - reopening roughly $2 / 3$ of the SES investment gap. Columns (2) and (3) show that the effect of the priming among those with prior experience with the program is entirely driven by low-SES parents (significant at the $5 \%$ level), consistent with the psychological mechanism ( $\mathrm{p}$-value of the difference $=$ 0.145). This pattern rules out that the priming merely decreases trust in public schools - what would decrease willingness to invest across all primed parents. Moreover, priming financial worries has no significant effects on parents without prior experience with the program (whose willingness to invest was already low), ruling out that it merely leads the poor to 'optimally' save (even if the endowment is quite small) for other planned educational expenses outside the experiment, in 
case they believe that textbooks and uniforms are no longer free. Treatment effects are extremely robust to including socio-demographic characteristics and controlling flexibly for predicted returns (column 4), and to allowing the effects of priming to vary with predicted returns (column 5). 
Table 1 -Effects of prior experience and priming on willingness to invest

\begin{tabular}{|c|c|c|c|c|c|}
\hline & \multicolumn{5}{|c|}{ Information $=0$} \\
\hline & $\begin{array}{l}\text { Overall } \\
\text { (1) }\end{array}$ & $\begin{array}{c}\text { Low-SES } \\
(2)\end{array}$ & $\begin{array}{c}\text { High-SES } \\
(3)\end{array}$ & $\begin{array}{l}\text { Overall } \\
\text { (4) }\end{array}$ & $\begin{array}{c}\text { Overall } \\
(5)\end{array}$ \\
\hline Prior experience & $\begin{array}{c}0.180^{* * *} \\
(0.0413)\end{array}$ & $\begin{array}{c}0.195^{* * *} \\
(0.0439)\end{array}$ & $\begin{array}{c}0.052 \\
(0.1223)\end{array}$ & $\begin{array}{c}0.190^{* * *} \\
(0.0420)\end{array}$ & $\begin{array}{c}0.191^{* * *} \\
(0.0420)\end{array}$ \\
\hline Priming x Prior experience & $\begin{array}{c}-0.108^{*} \\
(0.0588)\end{array}$ & $\begin{array}{c}-0.140^{* *} \\
(0.0626)\end{array}$ & $\begin{array}{c}0.121 \\
(0.1699)\end{array}$ & $\begin{array}{c}-0.121^{* *} \\
(0.0597)\end{array}$ & $\begin{array}{c}-0.119^{*} \\
(0.0664)\end{array}$ \\
\hline Priming & $\begin{array}{c}0.042 \\
(0.0445)\end{array}$ & $\begin{array}{c}0.061 \\
(0.0473)\end{array}$ & $\begin{array}{c}-0.106 \\
(0.1313)\end{array}$ & $\begin{array}{c}0.056 \\
(0.0453)\end{array}$ & $\begin{array}{c}0.025 \\
(0.0520)\end{array}$ \\
\hline Priming x Prior experience $\mathrm{x}$ Predicted returns & & & & & $\begin{array}{c}-0.127 \\
(1.1178)\end{array}$ \\
\hline Priming x Predicted returns & & & & & $\begin{array}{c}1.245 \\
(1.0106)\end{array}$ \\
\hline p-value (Priming $x$ Prior exp. $[$ low-SES $]=[$ high-SES $]$ ) & & & 45 & & \\
\hline Controls & No & No & No & Yes & Yes \\
\hline Predicted returns (cubic polynomial) & No & No & No & Yes & Yes \\
\hline Control group mean & 0.329 & 0.310 & 0.481 & 0.329 & 0.329 \\
\hline Observations & 1139 & 993 & 146 & 1122 & 1122 \\
\hline R-Squared & 0.019 & 0.022 & 0.018 & 0.024 & 0.026 \\
\hline
\end{tabular}

10 in airtime credit for 6 months of the SMS program, and 0 otherwise Regressions within sub-sample not informed over text message about child-specific predicted effects of the SMS program on attendance (Information $=0)$. Prior experience $=1$ if the subject was randomly assigned to the SMS program in the previous RCT, and 0 otherwise. Priming $=1$ if subject was primed about financial worries, and 0 otherwise. Child-specific predicted effects on graduation rates generated from Bettinger et al. (2020)'s experimental results, using machine learning techniques. Controls include student's race, age and gender, and their caregiver's race, age, income and schooling. Standard errors in parentheses. $* * * \mathrm{p}<0.01, * *$ $\mathrm{p}<0.05,{ }^{*} \mathrm{p}<0.1$. 


\section{B. Robustness checks}

Appendix E shows that our results are extremely robust to controlling flexibly for an alternative version of predicted returns, computed within a different subsample of parents in Bettinger et al. (2020) who received weekly nudges via text messages over the previous school year - without overlap with our participants' pool.

Most importantly, Appendix E shows that the effect size of financial worries on the likelihood of investment among those with prior experience with the program not only remains very large as we restrict attention to parents above the 25th, 50 th and 75 th percentiles of predicted returns, but also, remains largely stable and precisely estimated - despite the progressively smaller sample sizes. This supports the claim that financial worries lead poor parents to sub-optimally under-invest in face of large returns: for parents at the 75th percentile, risk aversion would have to be implausibly large to justify such a small certainty equivalent, as the expected value of the investment for those parents is roughly 350 -fold that of the outside option (see Appendix B).

\section{Attention misallocation}

This section turns to the mechanism behind the effects of financial worries on investment decisions. We start by testing whether financial worries reallocate attention to short-term rewards in subsection V.A. with the help of incentivized

cognitive tests. Next, subsection V.B benchmarks the effects of the priming to those of framing program's returns as if they were small.

\section{A. Cognitive function: Responses to small but immediate returns}

Following Lichand and Mani (2020), we capture subjects' executive functions in our phone surveys with the help of audio cognitive tests. We use (1) digit span to measure attention and working memory, whereby subjects must recall digits from the sequences we play (the more digits accurately recalled, the higher the score); and (2) Stroop to measure attention and impulse control, whereby subjects must press the number of times they heard a particular digit repeated in a sequence (but not the digit itself). See Appendix A for the full script. Importantly, performance in those tests is incentivized: subjects are told they can earn extra $\mathrm{R} \$ 2$ (about 0.70 USD at the time) if they are amongst the $20 \%$ top-performers in those tests.

We test the hypothesis that financial worries lead poor subjects to respond to such small but immediate returns to a greater extent. Figure 1 summarizes the conclusions by focusing on the summary measure of cognitive performance (see Appendix $\mathrm{F}$ for all details), separately for low-SES parents (Panel A) and highSES ones (Panel B). Among low-SES subjects (Panel A), priming financial worries shifts the distribution of the summary measure of cognitive outcomes to the right $(\mathrm{p}=0.02)$. The effect size is large, equivalent to $1 / 3$ that of college education. 
Consistent with the psychological mechanism, priming does not significantly shift cognitive performance among high-SES parents $(\mathrm{p}=0.74$; Panel B).

Figure 1. Effects of financial worries on cognitive performance, by SES

Panel A: Low-SES parents

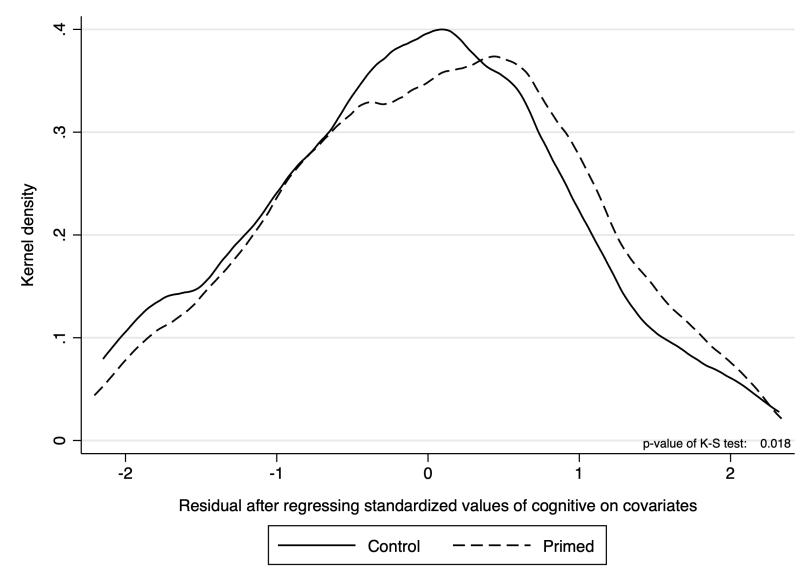

Panel B: High-SES parents

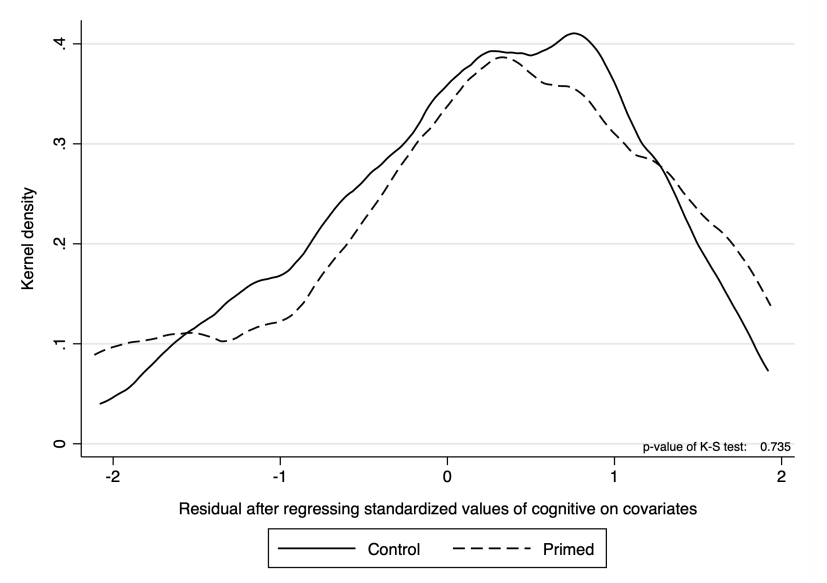

Notes: Kernel density plots of the cognitive performance summary measure residualised with respect to controls, separately for low-SES parents (Panel A) and high-SES ones (Panel B). Controls include student's race, age and gender, and their caregiver's race, age, income and schooling. P-values of KolmogorovSmirnov tests of equality of distribution for subjects primed and not primed within each panel. 
B. Benchmarking: Responses to framing future returns as small

Figure G4 in Appendix G showcases that the informational intervention decreased willingness to invest in the SMS program, relative to the control group. Table 2 formally estimates the effect of informing parents about the effects of the program on the probability of investing in it, symmetrically to equation 1 , restricting attention to the control group of the survey experiment at first. Column (1) shows that information decreases the likelihood of investment by 13.1 p.p. among parents with prior experience with the program (significant at the $5 \%$ level), a slightly larger effect size than that of the priming in Table 1. Columns (2) and (3) show that, just as in the case of the priming, the effect of framing the returns of the program as small is entirely driven by low-SES parents (significant at the $5 \%$ level; p-value of the difference $=0.34$ ). Once again, treatment effects are extremely robust to including socio-demographic characteristics and controlling flexibly for predicted returns (column 4), and to allowing the effects of information to vary with predicted returns (column 5). Last, column (6) estimates the full-interaction model; we do not reject the hypothesis that the effect of the priming and that of information are statistically identical $(\mathrm{p}=0.68)$. 
Table 2-Effects of prior experience and priming on willingness to invest

\begin{tabular}{|c|c|c|c|c|c|c|}
\hline & \multicolumn{5}{|c|}{ Priming $=0$} & \multirow{2}{*}{$\begin{array}{c}\text { Full sample } \\
\qquad \begin{array}{l}(6)\end{array}\end{array}$} \\
\hline & $\begin{array}{l}\text { Overall } \\
\text { (1) }\end{array}$ & $\begin{array}{c}\text { Low-SES } \\
(2)\end{array}$ & $\begin{array}{l}\text { High-SES } \\
\text { (3) }\end{array}$ & $\begin{array}{l}\text { Overall } \\
(4)\end{array}$ & $\begin{array}{l}\text { Overall } \\
(5)\end{array}$ & \\
\hline Prior experience & $\begin{array}{c}0.180^{* * *} \\
(0.0412)\end{array}$ & $\begin{array}{c}0.195^{* * *} \\
(0.0437)\end{array}$ & $\begin{array}{c}0.052 \\
(0.1232)\end{array}$ & $\begin{array}{c}0.192^{* * *} \\
(0.0417)\end{array}$ & $\begin{array}{r}0.192^{* * *} \\
(0.0417)\end{array}$ & $\begin{array}{c}0.188^{* * *} \\
(0.0413)\end{array}$ \\
\hline Information $\mathrm{x}$ Prior experience & $\begin{array}{r}-0.131^{* *} \\
(0.0596)\end{array}$ & $\begin{array}{c}-0.151^{* *} \\
(0.0629)\end{array}$ & $\begin{array}{c}0.034 \\
(0.1878)\end{array}$ & $\begin{array}{c}-0.146^{* *} \\
(0.0603)\end{array}$ & $\begin{array}{l}-0.130^{*} \\
(0.0676)\end{array}$ & $\begin{array}{c}-0.143^{* *} \\
(0.0598)\end{array}$ \\
\hline Information & $\begin{array}{c}0.033 \\
(0.0463)\end{array}$ & $\begin{array}{c}0.048 \\
(0.0487)\end{array}$ & $\begin{array}{c}-0.081 \\
(0.1493)\end{array}$ & $\begin{array}{c}0.045 \\
(0.0469)\end{array}$ & $\begin{array}{c}0.032 \\
(0.0543)\end{array}$ & $\begin{array}{c}0.042 \\
(0.0464)\end{array}$ \\
\hline Information $\mathrm{x}$ Prior experience $\mathrm{x}$ Predicted returns & & & & & $\begin{array}{c}-0.643 \\
(1.1831)\end{array}$ & \\
\hline Information $\mathrm{x}$ Predicted returns & & & & & $\begin{array}{c}0.529 \\
(1.0947)\end{array}$ & \\
\hline Priming $\mathrm{x}$ Prior experience & & & & & & $\begin{array}{c}-0.118^{* *} \\
(0.0587)\end{array}$ \\
\hline Priming & & & & & & $\begin{array}{c}0.050 \\
(0.0444)\end{array}$ \\
\hline Priming $\mathrm{x}$ Prior experience $\mathrm{x}$ Information & & & & & & $\begin{array}{l}0.175^{* *} \\
(0.0843)\end{array}$ \\
\hline Priming $\mathrm{x}$ Information & & & & & & $\begin{array}{l}-0.090 \\
(0.0645)\end{array}$ \\
\hline $\begin{array}{l}\text { p-value }(\text { Info x Prior exp. }[\text { low-SES }=\text { high-SES }]) \\
\text { p-value }([\text { Info x Prior exp. }]=[\text { Priming x Prior exp. }])\end{array}$ & & & & & & 0.681 \\
\hline Controls & No & No & No & Yes & Yes & Yes \\
\hline Predicted returns (cubic polynomial) & No & No & No & Yes & Yes & No \\
\hline Control group mean & 0.329 & 0.310 & 0.481 & 0.329 & 0.329 & 0.329 \\
\hline Observations & 1125 & 998 & 127 & 1115 & 1115 & 2223 \\
\hline R-Squared & 0.020 & 0.022 & 0.008 & 0.032 & 0.032 & 0.020 \\
\hline
\end{tabular}

Notes: All columns are OLS regressions with dependent variable $=1$ if the subject chose to exchange $\mathrm{R} \$ 10$ in airtime credit for 6 months of the SMS program, and 0 otherwise. Prior experience $=1$ if the subject was randomly assigned to the SMS program in the previous RCT, and 0 otherwise. Information $=1$ if the subject was informed over text message about child-specific predicted effects of the SMS program on attendance, and 0 otherwise. Priming $=1$ if subject was primed about financial worries, and 0 otherwise. Child-specific predicted effects on graduation rates generated from Bettinger et al. (2020)'s experimental results, using machine learning techniques. Controls include student's race, age and gender, and their caregiver's race, age, income and schooling. Standard errors in parentheses. ${ }^{* * *} \mathrm{p}<0.01,{ }^{* *} \mathrm{p}<0.05,{ }^{*} \mathrm{p}<0.1$. 


\section{Concluding remarks}

In a lab-in-the-field experiment in which parents had the opportunity to invest in a real educational program for their children in the absence of liquidity constraints, we documented that financial worries led poor parents to focus on small but immediate rewards at the expense of large future investment returns. The fact that primed low-SES parents under-invest relative to high-SES ones even when returns are very high is evidence that poverty-induced attention misallocation leads to inefficiency.

The fact that financial worries induce the poor to under-invest even when they have the means to finance those investments and even when they can commit (to overcome present-bias) is relevant as governments and civil society organizations now try to facilitate human capital investments through several financial instruments, in the hopes of allowing the poor to break away from poverty traps. Among credit lines to finance human capital investments, the PLUS programme in the United States represented 15\% of federal borrowing in 2015 (Kargar and Mann, 2018) 14 Among voucher programs to fund private school fees, several cover only part of the total costs (in the US, see the Milwaukee Parental Choice program, in Rouse, 1998; in developing countries, see PACES in Columbia, in Angrist, Bettinger and Kremer, 2006, and the Chilean voucher system in McEwan and Carnoy, 2000, and McEwan, 2001). Our findings suggest that such programs might be insufficient if poverty leads parents to respond inefficiently to future investment returns because it captures their attention to present needs.

An especially dramatic implication of our findings is that poverty's psychological effects are more likely to kick in precisely when the poor are presumably better equipped to make informed investment decisions - as priming effects are concentrated on low-SES parents with prior experience with the SMS program. In effect, poor parents often fail to take advantage of educational and health investments even when informed about their returns 15

As such, adapting the environment to the psychology of the poor, either by making long-term returns top-of-mind, or by making decisions automatic (such as by granting universal access to educational programs funded by governments or third-party organizations), may be key to mitigate the effects of attention misallocation - in particular when it comes to investments in children, linked to inter-generational poverty traps.

\footnotetext{
${ }^{14}$ In developing countries, see for instance the school fee loan program by Opportunity International (https://opportunity.org/what-we-do/education-finance/lending-for-education).

${ }^{15}$ While Jensen (2010) and Dizon-Ross (2019) document sizeable responses to information on returns to investments in children, Kremer and Holla (2009) and Kremer and Glennerster (2011) discuss several examples in education and health for which even informed parents under-invest.
} 


\section{REFERENCES}

Agostinelli, Francesco, Morteza Saharkhiz, and Matthew J Wiswall. 2020. "Home and School in the Development of Children. NBER Working Paper No. 26037." National Bureau of Economic Research.

Allcott, Hunt, Benjamin B Lockwood, and Dmitry Taubinsky. 2019. "Should we tax sugar-sweetened beverages? An overview of theory and evidence." Journal of Economic Perspectives, 33(3): 202-27.

Angrist, Joshua, Eric Bettinger, and Michael Kremer. 2006. "Long-term educational consequences of secondary school vouchers: Evidence from administrative records in Colombia." American economic review, 96(3): 847-862.

Athey, Susan, and Guido W Imbens. 2017. "The state of applied econometrics: Causality and policy evaluation." Journal of Economic Perspectives, 31(2): 3-32.

Bai, Liang, Benjamin Handel, Edward Miguel, and Gautam Rao. 2017. "Self-control and demand for preventive health: Evidence from hypertension in India." Review of Economics and Statistics, 1-55.

Barnard, Wendy Miedel. 2004. "Parent involvement in elementary school and educational attainment." Children and youth services review, 26(1): 39-62.

Becker, Gary S, and Nigel Tomes. 1979. "An equilibrium theory of the distribution of income and intergenerational mobility." Journal of political Economy, 87(6): 1153-1189.

Benjamin, Daniel J, James J Choi, and A Joshua Strickland. 2010. "Social identity and preferences." American Economic Review, 100(4): 191328.

Bessone, Pedro, Gautam Rao, Frank Schilbach, Heather Schofield, and Mattie Toma. 2020. "The economic consequences of increasing sleep among the urban poor." National Bureau of Economic Research.

Bettinger, E, N Cunha, G Lichand, and R Madeira. 2020. "Are the Effects of Informational Interventions Driven by Salience?" University of Zurich, Department of Economics Working Paper 350.

Burlacu, Sergiu, Anandi Mani, Piero Ronzani, and Lucia Savadori. 2019. "Psychology of poverty, financial incentives and parental investment in early childhood."

Callen, Michael, Mohammad Isaqzadeh, James D Long, and Charles Sprenger. 2014. "Violence and risk preference: Experimental evidence from Afghanistan." American Economic Review, 104(1): 123-48. 
Chernozhukov, Victor, Mert Demirer, Esther Duflo, and Ivan Fernandez-Val. 2018. "Generic machine learning inference on heterogenous treatment effects in randomized experiments." National Bureau of Economic Research.

Cohen, Jessica, Pascaline Dupas, and Simone Schaner. 2015. "Price subsidies, diagnostic tests, and targeting of malaria treatment: evidence from a randomized controlled trial." American Economic Review, 105(2): 609-45.

Cohn, Alain, Ernst Fehr, and Lorenz Goette. 2013. "Fair wages and effort provision: combining evidence from the lab and the field." University of Zurich Department of Economics Working Paper, , (107).

Cohn, Alain, Jan Engelmann, Ernst Fehr, and Michel André Maréchal. 2015. "Evidence for countercyclical risk aversion: An experiment with financial professionals." American Economic Review, 105(2): 860-85.

Dean, Joshua T. 2019. "Noise, cognitive function, and worker productivity." mimeo.

Diamond, Adele. 2013. "Executive functions." Annual review of psychology, 64: $135-168$.

Dizon-Ross, Rebecca. 2019. "Parents' beliefs about their children's academic ability: Implications for educational investments." American Economic Review, 109(8): 2728-65.

Fan, Xitao, and Michael Chen. 2001. "Parental involvement and students' academic achievement: A meta-analysis." Educational psychology review, 13(1): 1-22.

Fryer, Roland G, Steven D Levitt, John A List, et al. 2015. "Parental incentives and early childhood achievement: A field experiment in Chicago heights." National Bureau of Economic Research.

Gilad, Dalia, and Doron Kliger. 2008. "Priming the risk attitudes of professionals in financial decision making." Review of Finance, 12(3): 567-586.

Haushofer, Johannes, and Ernst Fehr. 2014. "On the psychology of poverty." science, 344(6186): 862-867.

Houtenville, Andrew J, and Karen Smith Conway. 2008. "Parental effort, school resources, and student achievement." Journal of Human resources, 43(2): 437-453.

Jensen, Robert. 2010. "The (perceived) returns to education and the demand for schooling." The Quarterly Journal of Economics, 125(2): 515-548.

Kahneman, Daniel. 2011. Thinking, fast and slow. Macmillan. 
Kargar, Mahyar, and William Mann. 2018. "Student loans, marginal costs, and markups: Estimates from the plus program."

Kaur, Supreet, Sendhil Mullainathan, Suanna Oh, and Frank Schilbach. 2021. "Do Financial Concerns Make Workers Less Productive?" National Bureau of Economic Research.

Kling, J, J Liebman, and L Katz. 2007. "Experimental analysis of neighborhood effects." Econometrica, 75(1): 83-119.

Kraft, Matthew A, and Todd Rogers. 2015. "The underutilized potential of teacher-to-parent communication: Evidence from a field experiment." Economics of Education Review, 47: 49-63.

Kremer, Michael, and Alaka Holla. 2009. "Improving education in the developing world: what have we learned from randomized evaluations?" Annu. Rev. Econ., 1(1): 513-542.

Kremer, Michael, and Rachel Glennerster. 2011. "Improving health in developing countries: evidence from randomized evaluations." In Handbook of health economics. Vol. 2, 201-315. Elsevier.

Kremer, Michael, Gautam Rao, and Frank Schilbach. 2019. "Behavioral development economics." In Handbook of Behavioral Economics: Applications and Foundations 1. Vol. 2, 345-458. Elsevier.

Lerner, Jennifer S, Ye Li, Piercarlo Valdesolo, and Karim S Kassam. 2015. "Emotion and decision making." Annual review of psychology, 66.

Lichand, Guilherme, and Anandi Mani. 2020. "Cognitive droughts." University of Zurich, Department of Economics, Working Paper, , (341).

Mani, Anandi, Sendhil Mullainathan, Eldar Shafir, and Jiaying Zhao. 2013. "Poverty impedes cognitive function." science, 341(6149): 976-980.

McEwan, Patrick J. 2001. "The effectiveness of public, catholic, and nonreligious private schools in Chile's voucher system." Education economics, 9(2): 103-128.

McEwan, Patrick J, and Martin Carnoy. 2000. "The effectiveness and efficiency of private schools in Chile's voucher system." Educational evaluation and policy analysis, 22(3): 213-239.

Mullainathan, Sendhil, and Eldar Shafir. 2013. Scarcity: Why having too little means so much. Macmillan.

Nye, Chad, Herb Turner, and Jamie Schwartz. 2006. "Approaches to parent involvement for improving the academic performance of elementary school age children." Campbell Systematic Reviews, 2(1): 1-49. 
Rouse, Cecilia Elena. 1998. "Private school vouchers and student achievement: An evaluation of the Milwaukee Parental Choice Program." The Quarterly journal of economics, 113(2): 553-602.

Schilbach, Frank, Heather Schofield, and Sendhil Mullainathan. 2016. "The psychological lives of the poor." American Economic Review, 106(5): 43540 .

Schofield, Heather. 2014. "The economic costs of low caloric intake: Evidence from India." Unpublished Manuscript.

Shah, Anuj K, Eldar Shafir, and Sendhil Mullainathan. 2015. "Scarcity frames value." Psychological science, 26(4): 402-412.

Shah, Anuj K, Sendhil Mullainathan, and Eldar Shafir. 2019. "An exercise in self-replication: Replicating Shah, Mullainathan, and Shafir (2012)." Journal of Economic Psychology, 75: 102127.

Thaler, Richard H. 1999. "Mental accounting matters." Journal of Behavioral decision making, 12(3): 183-206.

Wager, Stefan, and Susan Athey. 2018. "Estimation and inference of heterogeneous treatment effects using random forests." Journal of the American Statistical Association, 113(523): 1228-1242.

York, Benjamin N, and Susanna Loeb. 2014. "One step at a time: The effects of an early literacy text messaging program for parents of preschoolers." National Bureau of Economic Research.

York, Benjamin N, Susanna Loeb, and Christopher Doss. 2019. "One step at a time the effects of an early literacy text-messaging program for parents of preschoolers." Journal of Human Resources, 54(3): 537-566. 


\section{Online Appendix A - Phone Survey Script}

\section{A1. Outcomes}

\section{FINANCIAL WORRIES}

"How worried are you about not having money to pay all household bills at the end of this month? If you are not worried at all, press 0 ; if you are somewhat worried, press 1; if you are very worried, press 2; or if you are desperate, press 3."

\section{INVESTMENT DECISION}

"You already earned $\mathrm{R} \$ 10$ in airtime credit by answering this call until the end. Would you rather exchange those $\mathrm{R} \$ 10$ for 6 months of weekly text messages about your child's school life? If you would like to exchange airtime by the text messages, press 1 ; if you would like to keep the airtime, press 2 ; or to listen again, press 9."

\section{COGNITIVE TESTS}

Stroop: "Answer as fast as you can: how many times is each digit repeated in the following strings? Answer the number of repetitions, not the number itself."

(A) 9999 ; (B) 66666 ; (C) 000 ; (D) 44444 .

Digit span: "Please type the sequence of digits exactly as you hear them."

(A) 4820 5; (B) 52917 ; (C) 97381 5; (D) 062764 .

\section{A2. Treatment and control conditions across the experiments}

\section{PREVIOUS RCT}

Control group: At most 1 school-wide SMS every other week, with communication about school activities.

Treatment group: 1 SMS per week from the school with child-specific information or salience messages (see Bettinger et al., 2020).

\section{SURVEY EXPERIMENT}

Control group: "Please tell us after the tone what you would do if your child's school started charging $\mathrm{R} \$ 20$ for school uniforms, payable by the end of this month?"

Treatment group: "Please tell us after the tone what you would do if your child's school started charging $\mathrm{R} \$ 400$ for school uniforms, payable by the end of this month?" 


\section{INFORMATION EXPERIMENT}

Control group: "Last year, over 19,000 families in the State of São Paulo received weekly text messages about their children's school life."

Treatment group: "Last year, we found out that sending messages about your child's school life has the potential to decrease his/her absences by $0 / 1 / 2 / 3$ over the course of six months." 


\section{Online Appendix B - Additional Details on Predicted Returns}

\section{B1. Causal random forests: predicted effects on graduation rates}

Following Wager and Athey (2018), we implement causal random forests to estimate child-specific predicted impacts of the SMS program, evaluated in the previous RCT, on the probability of grade promotion. Causal forests estimate heterogeneity in treatment effects by splitting the data in partitions for which treatment effects are the largest. We estimate honest trees - holding out nonoverlapping test samples - to prevent biased estimates from over-fitting.

Concretely, we apply the causal random forest algorithm to a subset of the parents in Bettinger et al. (2020): those assigned to child-specific information or salience messages, and those in the pure control group. We exclude those assigned to the within-classroom control group because of spillovers, and those assigned to the nudge experiment because of baseline imbalances (we turn to those in Appendix B.B3). The final sub-sample consists of 10,264 students.

The primary dependent variable of our analysis is whether the child has been promoted to the next grade. The set of covariates used to estimate the heterogeneous treatment effects, $\beta_{i}$, includes student race, age, gender, first quarter's math and Portuguese attendance and GPA, and their caregiver's race, age, family tie, income and schooling.

A fundamental identifying assumption of this algorithm is unconfoundedness, i.e. $\{Y(1), Y(0)\} \perp T \mid X$, where $T$ denotes the treatment indicator variable, $X$ denotes the covariate's vector and $Y$ is the outcome vector. In other words, it implies that the treatment indicator is independent of potential outcomes, after controlling for the covariate vector. This assumption is satisfied by random assignment; Bettinger et al. (2020) documents that the different groups were balanced according to students' and their caregivers' baseline characteristics.

We trained the forest on $80 \%$ of the sample and used default tuning parameters, clustering standard errors at the classroom level. For each tree's split, the forest evaluates the extent of heterogeneity in treatment effect by each covariate, and splits each tree on the variable that maximizes such heterogeneity. Table B1 documents each covariate's importance, defined as how often each variable was used in a tree split, across all tress. Student baseline Portuguese and math GPA are the two most often used features in predicting heterogeneous treatment effects in our estimates, with $35.6 \%$ and $24.8 \%$ of the splits based on those, respectively.

We assess the quality of our forest's estimates using a test motivated by Chernozhukov et al. (2018). The idea is to fit conditional average treatment effects (CATE), $\tau(x)=E[Y(1)-Y(0) \mid X=x]$, as a linear function of the predictions and apply a heteroskedasticity-consistent test of calibration. Two predictions are produced, Mean forest prediction and Differential forest prediction. The coefficient of the latter can be used to test hypothesis of heterogeneity of treatment effects. Results, presented in table $\overline{B 2}$, suggest that this is the case $(p=0.05)$.

Last, Figure B1 displays the density of the predicted effects of the SMS program 
Table B1-Variables' importance

\begin{tabular}{lc}
\hline \hline & Importance \\
\hline Portuguese GPA & 0.356 \\
Math GPA & 0.248 \\
Portuguese attendance & 0.120 \\
Math attendance & 0.110 \\
Student's age & 0.095 \\
Caregiver's age & 0.045 \\
Student's gender & 0.006 \\
Student's color & 0.006 \\
Caregiver's schooling & 0.005 \\
Caregiver's income & 0.003 \\
Caregiver's color & 0.003 \\
Caregiver's gender & 0.002 \\
\hline
\end{tabular}

Notes: Importance of the variables in training the forest indicates how often a variable was used in a tree split. The variables are ordered by importance, with larger values indicating greater importance. Parameters of the forest training: num.trees $=2000$, honesty $=$ True, clusters $=$ classroom, seed $=123$ and others at default setting.

on the probability of grade promotion for our study participants, based on the causal forest's estimates summarized in this Appendix.

\section{B2. Details on computation of returns on investment}

To give a rough sense of child-specific returns on investment, we can convert child-specific predicted effects of the SMS program on graduation rates into its predicted impacts on the present value of life-long earnings, using the correlation between one additional year of schooling and monthly earnings in the 2017 Brazil National Household Survey (Pesquisa Nacional por Amostra de Domicilios, PNAD) from the Brazilian Institute of Geography and Statistics (Instituto Brasileiro de Geografia e Estatística, IBGE). Concretely, we sum over this average monthly earnings differential ( $\mathrm{R} \$ 135.76)$ from ages 18 to 65 (the active work ages), discounting flows by the yearly interest rate (fixed at $9.74 \%$, the average yearly basic interest rate in Brazil over 2017), and then scale this value by child-specific predict impacts of the program on graduation rates. Subtracting this expected present value by the value of the outside option (that of keeping the $R \$ 10$ endowment as airtime credit) yields the expected net present value of 
Figure B1. Predicted treatment effects of the program on child's grade promotion

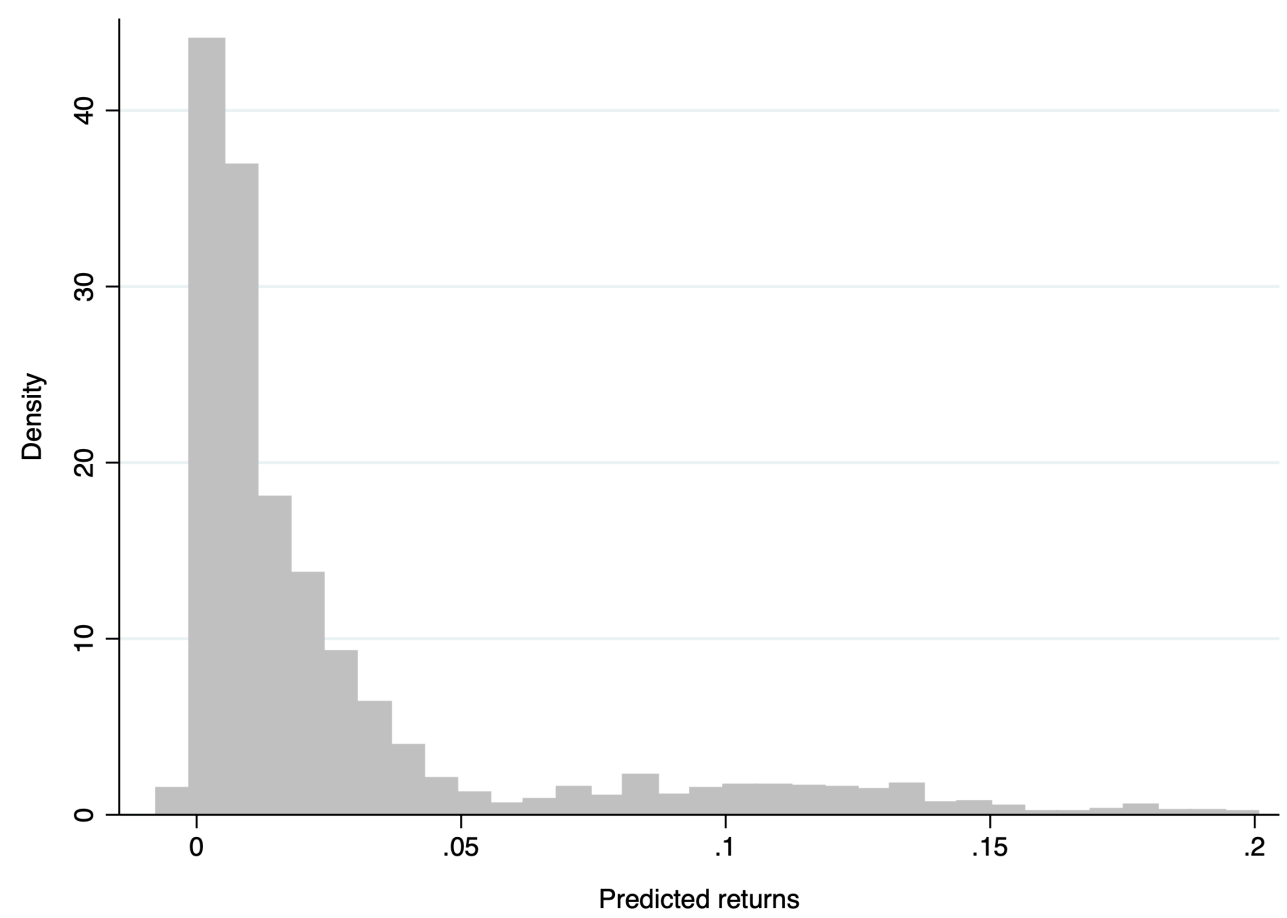

Notes: Density of child-specific predicted treatment effects of the SMS program on grade promotion, using causal random forests. $\beta_{i}$ is the predicted treatment effect for family i, estimated as a function of child's and caretaker's race, age and gender, of family's socioeconomic status, of caretaker's education and child's grades and attendance. Parameters of the forest training: num.trees $=2000$, honesty $=$ True, clusters $=$ classroom, seed $=123$ and others at default setting. 
Table B2-Assessing forest's goodness of fit

\begin{tabular}{lcccc}
\hline \hline & Estimate & Std. Error & t-stat & p-value \\
$(1)$ & $(2)$ & $(3)$ & $(4)$ \\
\hline Mean forest prediction & 1.01 & 0.51 & 1.98 & 0.02 \\
Differential forest prediction & 0.74 & 0.46 & 1.62 & 0.05 \\
\hline
\end{tabular}

Notes: Best linear fit using forest predictions (on held-out data) as well as the mean forest prediction as regressors, along with one-sided heteroskedasticityrobust standard errors. A coefficient of 1 for Mean forest prediction suggests that the average prediction produced by the forest is correct; and a coefficient of 1 for Differential forest prediction suggests that the forest has captured heterogeneity in the underlying signal. The p-value of the latter coefficient also serves as an Omnibus test: if the coefficient is greater than 0, then we can reject the null of no heterogeneity. Parameters of the forest training: num.trees $=2000$, honesty $=$ True, clusters $=$ classroom, seed $=123$ and others at default setting.

the investment.

This procedure provides only a rough approximation for a variety of reasons. It assumes, for instance, that parents discount the future by the same extent as the basic interest rate, that parents care about their children's future earnings as much as they care about their current consumption (perfect altruism), that the correlation between one additional year of educational attainment and earnings is similar to the causal effect of an additional school year on earnings, and that the program increases the likelihood of an additional school year but not more. Subtracting the present cost from the present value of investment returns further assumes that parents are risk neutral.

Having said that, the yearly earnings differential from an additional school year is so large that, despite high interest rates, the net present value of an additional school year is $R \$ 12,504.08$. While this yields a negative return on investment (ROI) for the study participant with the minimal predicted effect of the program on graduation rates $(-0.8 \%)$, the ROI at the 25 th percentile (a $0.4 \%$ increase in graduation rates) is already $R \$ 44$ (over 4 -fold the investment cost); at the median (a 1.1\% increase in graduation rates), $\mathrm{R} \$ 125$ (over 12 -fold the investment cost); at the 75 th percentile (a $2.8 \%$ increase in graduation rates), $\mathrm{R} \$ 335$ (over 33 -fold the investment cost); and for the study participant with the maximal predicted effect of the program (23.9\%), $\mathrm{R} \$ 2,981$ (almost 300-fold its cost).

\section{B3. Alternative predicted effects on graduation rates}

To assess the robustness of our predictions, we also resort to an alternative version of predicted returns on graduation rates by training the causal forest on a 
different subset of parents - those assigned to the nudge experiment in Bettinger et al. (2020). This sub-sample has no overlap with our study participants.

As in Bettinger et al. (2020), we estimate treatment effects using differences-indifferences, contrasting treated students with the pure control group, before and after the onset of the nudges in the third school quarter, to deal with baseline imbalances between this sub-sample of treated parents and the pure control group. Estimating treatment effects on grade promotion with this strategy is challenging, because pass/fail status is only defined at the last school quarter.

To deal with this challenge, we compute a quarterly proxy of grade promotion by applying the end-of-year pass/fail criteria within each quarter: a student is eligble to advance to the next grade if $\mathrm{s} /$ he has a GPA above 5 (the minimum passing grade; GPA ranges from 0 to 10) and attendance above $75 \%$ in each subject. Since we only have data on math and Portuguese attendance and GPA, our proxy is based on those two subjects.

In sum, we predict child-specific treatment effects on graduation rates by combining the differences-in-differences strategy for the effects of the SMS program on our proxy of grade promotion with the causal random forest algorithm.

We first average over child-specific predicted differences between treatment and control on the first two school quarters - before the onset of the text messages -, to estimate the pre-treatment differences (if any). We then subtract the last quarter predicted returns of the program from such baseline differences, resulting in childspecific differences-in-differences estimates of the SMS program on graduation rates. Figure B2 displays the density of the predicted effects of the SMS program on the probability of grade promotion for our study participants, based on the causal forest's estimates summarized in this Appendix. 
Figure B2. Predicted treatment effects of the program on child's grade promotion

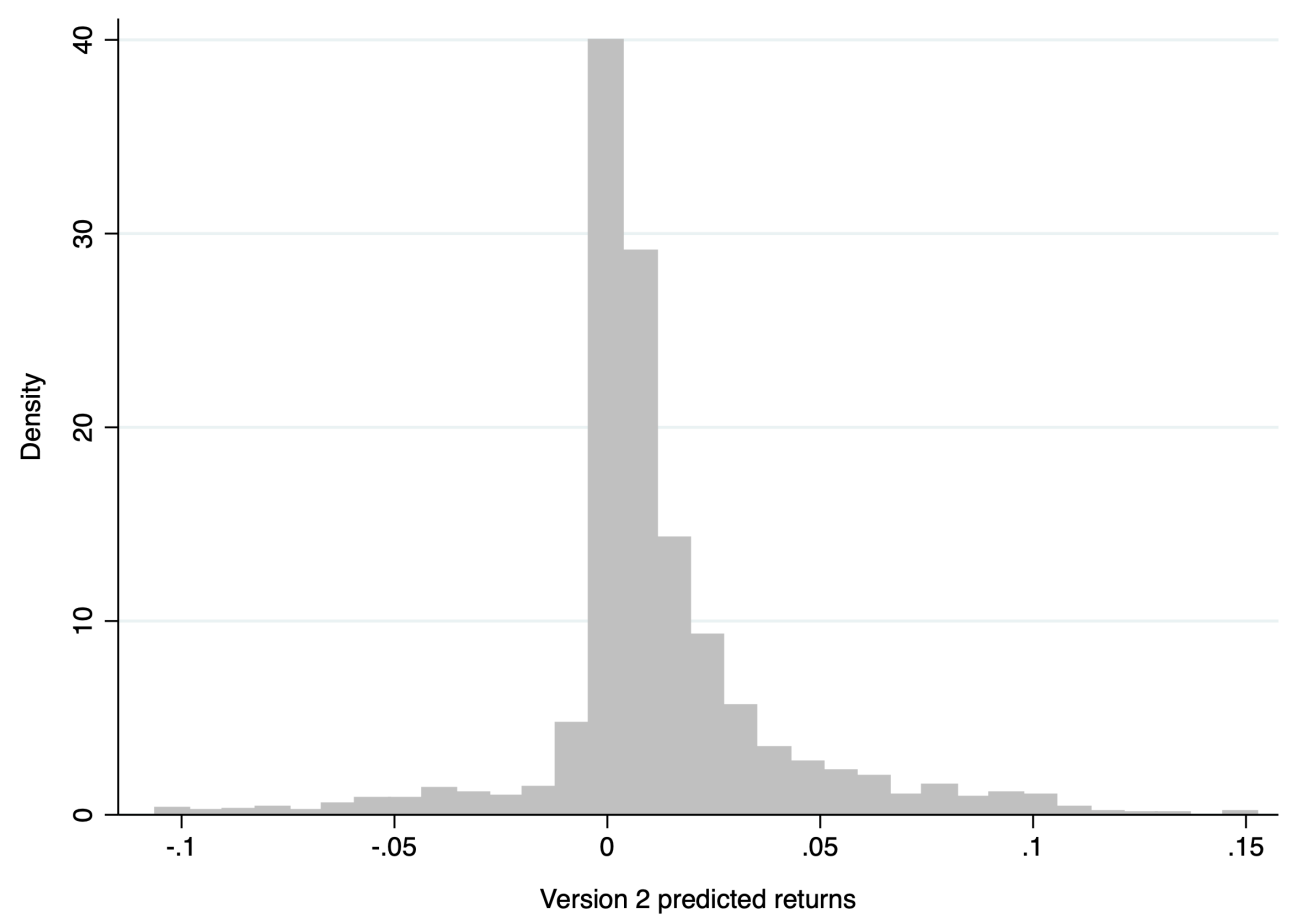

Notes: Density of child-specific predicted treatment effects on grade promotion (proxied by the pass/fail criteria within each quarter), restricting attention to the nudge experiment in Bettinger et al. (2020), combining a differences-in-differences strategy with causal random forests. $\beta_{i}$ is the predicted treatment effect for family i, estimated as a function of child's and caretaker's race, age and gender, of family's socioeconomic status, of caretaker's education and child's grades and attendance. Parameters of the forest training: num.trees $=2000$, honesty $=$ True, clusters $=$ classroom, seed $=123$ and others at default setting. 


\section{B4. Causal trees: predicted effects on attendance}

Following Athey and Imbens (2017), we implement regression trees to partition the sample into subgroups according to heterogeneity in treatment effects of the SMS program on student attendance. The regression tree estimation algorithm trades off goodness-of-fit against over-fitting to fine-tune the depth of the tree, that is, the complexity of how it partitions the data to predict individual-level treatment effects. While the procedure is known to over-fit in the case of extreme leaves, we were interested in the simplest possible prediction that is still statistically grounded. For our purposes, predicted heterogeneous treatment effects of the SMS program on student attendance provides an objective measure that could be tied to returns on investment and easily communicated to our study participants.

We use the algorithm to predict child-specific effects of the SMS program on math attendance, allowing the algorithm to estimate different treatment effects by all students' and primary caregivers' characteristics from the baseline survey in Bettinger et al. (2020).

Figure B3 displays the density of the predicted effects of the SMS program on 4th-quarter math attendance for our study participants, based on the causal trees' estimates summarized in this Appendix. As shown, the algorithm picks caregivers' age as the main dimension on which to partition the dataset, further allowing impacts to vary by student's gender in the case of caregivers between 33 and 40 years old (girls benefit more than boys, with 1 extra absence reduced by the program over the course of 6 months). 
Figure B3. Predicted treatment effects of the program on child's absences within 6 months

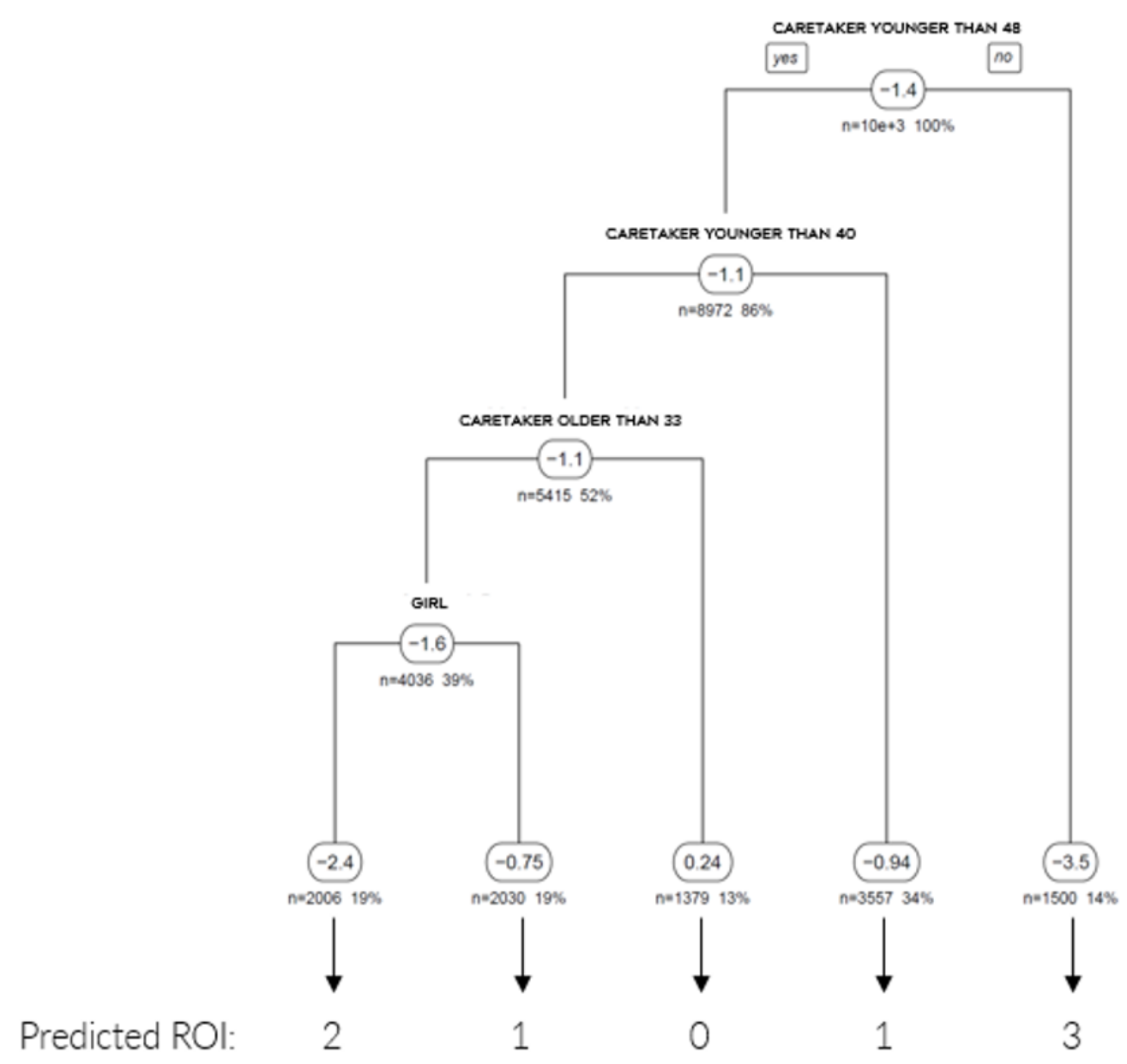

Notes: Predicted treatment effects of the SMS program on child's absences (rounded to the nearest integer), using a regression tree based on the estimates of Bettinger et al. (2020). $\beta_{i}$ is the predicted treatment effect for family i, estimated as a function of child's and caretaker's race, age and gender, of family's socioeconomic status and of caretaker's education. Parameters of the tree estimation: split.Rule $=$ "TOT", cv.option $=$ "fit", minsize $=250$, $\mathrm{cv}$. Honest $=\mathrm{F}$, split.Bucket $=\mathrm{T}, \mathrm{xval}=10$, propensity $=0.8$. 
Online Appendix C - Selective Non-Response and Balance Tests

This Appendix presents selective non-response and balance tests. Table C1 shows that while the take up of the phone survey is low on average, it is not systematically different across the different experimental arms. Reassuringly, it also showcases that treatment status within each of the three experiments was cross-randomized, as the coefficients of each treatment do not change when we control for all of them together (Column 4).

Tables C2, C3 and C4 compile balance tests for the survey experiment, the prior $\mathrm{RCT}$, and the information experiment, respectively. The tables display sample means of students' and caregivers' characteristics separately for the treatment and control groups within each experiment, along with statistical tests of equality of means across groups for each variable, and of joint statistical significance across all of them. We document that all experiments are balanced, with no systematic joint differences (given by F-tests) at conventional significance levels. For the few variables characterized by statistically significant imbalances within each experiment - consistent with the rate expected to happen just by chance -, differences are very small in magnitude, with no economic significance. 
Table C1 - Selective non-response tests

\begin{tabular}{lcccc}
\hline \hline & $(1)$ & $(2)$ & $(3)$ & $(4)$ \\
\hline Priming & 0.001 & & & 0.001 \\
& $(0.0056)$ & & & $(0.0056)$ \\
Prior experience & & 0.006 & & 0.006 \\
& & $(0.0057)$ & & $(0.0057)$ \\
Information & & & -0.006 & -0.006 \\
& & & $(0.0056)$ & $(0.0056)$ \\
\hline Control group mean & 0.112 & 0.109 & 0.116 & 0.112 \\
Observations & 12597 & 12597 & 12597 & 12597 \\
R-Squared & 0.000 & 0.000 & 0.000 & 0.000 \\
\hline
\end{tabular}

Notes: All columns are OLS regressions with dependant variable $=$ 1 if the subject answered the phone survey in full, and 0 otherwise. Priming $=1$ if subject was primed about financial worries, and 0 otherwise. Prior experience $=1$ if the subject was assigned to the treatment group in Bettinger et al. (2020), and 0 otherwise. Information $=1$ if the subject was informed over text message about child-specific predicted returns of the SMS program on attendance, and 0 otherwise. Standard errors in parentheses: *** $\mathrm{p}<0.01,{ }^{* *}$ $\mathrm{p}<0.05,{ }^{*} \mathrm{p}<0.1$. 
Table C2-Balance Tests: Not primed vs. Primed

\begin{tabular}{lccc}
\hline \hline & $\begin{array}{c}\text { Not primed } \\
(1)\end{array}$ & $\begin{array}{c}\text { Primed } \\
(2)\end{array}$ & $\begin{array}{c}\text { Difference } \\
(2)-(1)\end{array}$ \\
\hline Black or brown student & 0.404 & 0.421 & 0.016 \\
& $(0.015)$ & $(0.015)$ & $(0.021)$ \\
Black or brown caregiver & 0.413 & 0.429 & 0.016 \\
& $(0.015)$ & $(0.015)$ & $(0.021)$ \\
Student's age & 14.711 & 14.673 & -0.039 \\
& $(0.020)$ & $(0.020)$ & $(0.029)$ \\
Caregiver's age & 39.258 & 39.465 & 0.208 \\
& $(0.199)$ & $(0.224)$ & $(0.299)$ \\
Female student & 0.817 & 0.788 & $-0.029 *$ \\
& $(0.012)$ & $(0.012)$ & $(0.017)$ \\
Mother is the primary caregiver & 0.504 & 0.510 & 0.006 \\
& $(0.015)$ & $(0.015)$ & $(0.021)$ \\
Incomplete primary education & 0.271 & 0.265 & -0.006 \\
& $(0.013)$ & $(0.013)$ & $(0.019)$ \\
Less than 1 minimum wage & 0.172 & 0.168 & -0.005 \\
& $(0.011)$ & $(0.011)$ & $(0.016)$ \\
\hline p-value(F test of joint significance) & & & 0.64 \\
\hline
\end{tabular}

Notes: Priming $=1$ if subject was primed about financial worries, and 0 otherwise. Standard errors in parentheses: *** $\mathrm{p}<0.01,{ }^{*} \mathrm{p}<0.05$, * $\mathrm{p}<0.1$. 
Table C3-Balance Tests: No prior experience vs. Prior experience

\begin{tabular}{|c|c|c|c|}
\hline & $\begin{array}{c}\text { No prior experience } \\
(1)\end{array}$ & $\begin{array}{c}\text { Prior experience } \\
(2)\end{array}$ & $\begin{array}{l}\text { Difference } \\
(2)-(1)\end{array}$ \\
\hline Black or brown student & $\begin{array}{c}0.419 \\
(0.016)\end{array}$ & $\begin{array}{c}0.408 \\
(0.014)\end{array}$ & $\begin{array}{l}-0.012 \\
(0.021)\end{array}$ \\
\hline Black or brown caregiver & $\begin{array}{c}0.412 \\
(0.016)\end{array}$ & $\begin{array}{c}0.428 \\
(0.014)\end{array}$ & $\begin{array}{c}0.016 \\
(0.021)\end{array}$ \\
\hline Student's age & $\begin{array}{l}14.687 \\
(0.023)\end{array}$ & $\begin{array}{l}14.695 \\
(0.018)\end{array}$ & $\begin{array}{c}0.008 \\
(0.029)\end{array}$ \\
\hline Caregiver's age & $\begin{array}{l}39.244 \\
(0.225)\end{array}$ & $\begin{array}{l}39.443 \\
(0.200)\end{array}$ & $\begin{array}{c}0.199 \\
(0.304)\end{array}$ \\
\hline Female student & $\begin{array}{c}0.821 \\
(0.013)\end{array}$ & $\begin{array}{c}0.790 \\
(0.011)\end{array}$ & $\begin{array}{c}-0.031^{*} \\
(0.017)\end{array}$ \\
\hline Mother is the primary caregiver & $\begin{array}{c}0.504 \\
(0.016)\end{array}$ & $\begin{array}{c}0.509 \\
(0.014)\end{array}$ & $\begin{array}{c}0.005 \\
(0.022)\end{array}$ \\
\hline Incomplete primary education & $\begin{array}{c}0.269 \\
(0.015)\end{array}$ & $\begin{array}{c}0.267 \\
(0.012)\end{array}$ & $\begin{array}{l}-0.002 \\
(0.019)\end{array}$ \\
\hline Less than 1 minimum wage & $\begin{array}{c}0.166 \\
(0.012)\end{array}$ & $\begin{array}{c}0.173 \\
(0.010)\end{array}$ & $\begin{array}{c}0.006 \\
(0.016)\end{array}$ \\
\hline p-value(F test of joint significance) & & & 0.61 \\
\hline
\end{tabular}


Table C4-Balance Tests: Not informed vs. Informed

\begin{tabular}{lccc}
\hline \hline & $\begin{array}{c}\text { Not informed } \\
(1)\end{array}$ & $\begin{array}{c}\text { Informed } \\
(2)\end{array}$ & $\begin{array}{c}\text { Difference } \\
(2)-(1)\end{array}$ \\
\hline Black or brown student & 0.416 & 0.409 & -0.007 \\
Black or brown caregiver & $(0.015)$ & $(0.015)$ & $(0.021)$ \\
Student's age & 0.421 & 0.421 & -0.001 \\
& $(0.015)$ & $(0.015)$ & $(0.021)$ \\
Caregiver's age & 14.700 & 14.683 & -0.017 \\
& $(0.020)$ & $(0.021)$ & $(0.029)$ \\
Female student & 39.371 & 39.349 & -0.023 \\
& $(0.206)$ & $(0.218)$ & $(0.300)$ \\
Mother is the primary caregiver & 0.810 & 0.794 & -0.016 \\
Incomplete primary education & $(0.012)$ & $(0.012)$ & $(0.017)$ \\
& 0.496 & 0.518 & 0.022 \\
Less than 1 minimum wage & $(0.015)$ & $(0.015)$ & $(0.021)$ \\
& 0.277 & 0.259 & -0.017 \\
& $(0.013)$ & $(0.013)$ & $(0.019)$ \\
\hline p-value(F test of joint significance) & 0.189 & 0.150 & $-0.038^{* *}$ \\
\hline
\end{tabular}

Notes: Information $=1$ if subject was informed over text message about child-specific predicted returns of the SMS program on attendance, and 0 otherwise. Standard errors in parentheses: ${ }^{* * *} \mathrm{p}<0.01,{ }^{* *} \mathrm{p}<0.05,{ }^{*} \mathrm{p}<0.1$. 
Online Appendix D - Descriptive Statistics And Manipulation Tests

This Appendix compiles descriptive statistics, and manipulation tests for the survey experiment. Table D1 showcases the sample distribution across all experiments. Table D2 documents that the correlation between child-specific predicted effects of the SMS program on students' graduation rates and attendance is close to zero, as discussed in the main text. Next, Table D3 helps validate our usage of college education as a proxy for high socioeconomic status (SES): college education is four times more prevalent amongst high-income caregivers (those with monthly earnings of 3 minimum wages or higher) than among low-income ones.

Next, Table D4 documents differences in willingness to invest in the SMS program between low- and high-SES parents. High-SES parents are much more likely to undertake the investment: $48.2 \%$ of those invest in the SMS program, while only $31 \%$ of low-SES parents do so - a $35 \%$ SES investment gap.

Last, Tables D5 and D6 show that priming significantly increases financial worries on average, and especially so for low-SES parents. 
Table D1—Sample Distribution

\begin{tabular}{lccccc}
\hline \hline & \multicolumn{2}{c}{ Prior experience $=0$} & & \multicolumn{2}{c}{ Prior experience $=1$} \\
\cline { 2 - 3 } \cline { 5 - 6 } & $\begin{array}{c}\text { Priming }=0 \\
(1)\end{array}$ & $\begin{array}{c}\text { Priming }=1 \\
(2)\end{array}$ & & $\begin{array}{c}\text { Priming }=0 \\
(3)\end{array}$ & $\begin{array}{c}\text { Priming }=1 \\
(4)\end{array}$ \\
\hline Information $=0$ & 240 & 245 & 340 & 314 \\
Information $=1$ & 207 & 233 & 338 & 306 \\
\hline
\end{tabular}

Notes: The total sample size is 2,223 subjects. Priming $=1$ if subject was primed about financial worries, and 0 otherwise. Prior experience $=1$ if the subject was assigned to the treatment group in Bettinger et al. (2020), and 0 otherwise. Information $=1$ if the subject was informed over text message about child-specific predicted returns of the SMS program on attendance, and 0 otherwise. 
Table D2- Correlation between returns and info

\begin{tabular}{lc}
\hline \hline & $\rho$ \\
\hline Predicted returns on student's pass/fail status and attendance & -0.031 \\
Positive predicted returns on student's pass/fail status and attendance & 0.051 \\
\hline $\begin{array}{l}\text { Notes: Child-specific predicted returns on child's pass/fail status and school attendance } \\
\text { generated from Bettinger et al. (2020)'s experimental returns, using machine learning tech- } \\
\text { niques. }\end{array}$
\end{tabular}


Table D3-Proxy for SES

\begin{tabular}{lcc}
\hline \hline \multicolumn{2}{l}{ Panel A: Sample income distribution } & \\
\hline Income & Frequency & Percent \\
\hline$<1 \mathrm{MW}$ & 2118 & 16.82 \\
{$[1 \mathrm{MW}, 3 \mathrm{MW})$} & 5809 & 46.13 \\
{$[3 \mathrm{MW}, 6 \mathrm{MW})$} & 926 & 7.35 \\
{$[6 \mathrm{MW}, 11 \mathrm{MW})$} & 101 & 0.80 \\
$>11 \mathrm{MW}$ & 17 & 0.13 \\
Not reported & 3623 & 28.77 \\
Total & 12594 & 100.00 \\
\hline \hline
\end{tabular}

Panel B: Income vs. College education

\begin{tabular}{lcc}
\hline Income $\geq 3 \mathrm{MW}$ & \multicolumn{2}{c}{ College education } \\
\cline { 2 - 3 } & No & Yes \\
\hline No & 91.66 & 8.34 \\
Yes & 63.51 & 36.49 \\
Total & 88.38 & 11.62 \\
\hline
\end{tabular}

Notes: Income brackets defined by caregivers' monthly income from all sources, reported in minimum wages (MW). In Panel B, sample is restricted to subjects who reported income. 
Table D4-Low vs. High SES

\begin{tabular}{|c|c|c|c|c|c|}
\hline & Full sample & $\begin{array}{c}\text { Prior } \\
\text { experience }=0 \\
(2)\end{array}$ & Priming $=0$ & $\begin{array}{c}\text { Information }=0 \\
(4)\end{array}$ & $\begin{array}{c}\text { Information, } \\
\text { Priming and } \\
\text { Prior experience }=0 \\
(5)\end{array}$ \\
\hline High-SES & $\begin{array}{c}0.087^{* * *} \\
(0.0322)\end{array}$ & $\begin{array}{c}0.068 \\
(0.0498)\end{array}$ & $\begin{array}{c}0.083^{*} \\
(0.0464)\end{array}$ & $\begin{array}{c}0.080^{*} \\
(0.0438)\end{array}$ & $\begin{array}{c}0.172^{*} \\
(0.0958)\end{array}$ \\
\hline Control group mean & 0.396 & 0.339 & 0.405 & 0.413 & 0.310 \\
\hline Observations & 2223 & 925 & 1125 & 1139 & 240 \\
\hline R-Squared & 0.003 & 0.002 & 0.003 & 0.003 & 0.013 \\
\hline
\end{tabular}

Notes: All columns are OLS regressions with dependent variable $=1$ if the subject chose to exchange $\mathrm{R} \$ 10$ in airtime credit for 6 months of the SMS program, and 0 otherwise. High-SES $=1$ if the subject completed higher education, and 0 otherwise. Priming $=1$ if subject was primed about financial worries, and 0 otherwise. Prior experience $=1$ if the subject was assigned to the treatment group in Bettinger et al. (2020), and 0 otherwise. Information $=1$ if the subject was informed over text message about child-specific predicted returns of the SMS program on attendance, and 0 otherwise. Standard errors in parentheses. ${ }^{* * *} \mathrm{p}<0.01,{ }^{* *} \mathrm{p}<0.05$, $^{*}$ $\mathrm{p}<0.1$. 
Table D5-Effects on financial worries

\begin{tabular}{lcccc}
\hline \hline & $(1)$ & $(2)$ & $(3)$ & $(4)$ \\
\hline Priming & $0.083^{* * *}$ & $0.082^{* * *}$ & $0.080^{* * *}$ & $0.084^{* * *}$ \\
& $(0.0213)$ & $(0.0213)$ & $(0.0214)$ & $(0.0262)$ \\
Priming x Predicted returns & & & & -0.172 \\
& & & & $(0.5776)$ \\
\hline Controls & No & Yes & Yes & Yes \\
Predicted returns (cubic polynomial) & No & No & Yes & Yes \\
\hline Control group mean & 0.564 & 0.564 & 0.564 & 0.564 \\
Observations & 2103 & 2103 & 2071 & 2071 \\
R-Squared & 0.007 & 0.014 & 0.017 & 0.017 \\
\hline
\end{tabular}

Notes: All columns are OLS regressions with dependent variable $=1$ if the subject reported being very worried or desperate about paying household bills by the end of the month, and 0 otherwise. Priming $=1$ if subject was primed about financial worries, and 0 otherwise. Child-specific predicted effects on graduation rates generated from Bettinger et al. (2020)'s experimental results, using machine learning techniques. Controls include student's race, age and gender, and their caregiver's race, age, income and schooling. Standard errors in parentheses. ${ }^{* * *} \mathrm{p}<0.01,{ }^{* *} \mathrm{p}<0.05,{ }^{*} \mathrm{p}<0.1$. 
Table D6 - Effects on financial worries by SES

\begin{tabular}{lccccc}
\hline \hline & \multicolumn{3}{c}{ Very worried or desperate } & Desperate \\
\cline { 2 - 5 } & $(1)$ & $(2)$ & $(3)$ & $(4)$ & $(5)$ \\
\hline High-SES & 0.026 & 0.009 & 0.010 & 0.011 & 0.025 \\
& $(0.0471)$ & $(0.0478)$ & $(0.0479)$ & $(0.0480)$ & $(0.0376)$ \\
Priming & $0.083^{* * *}$ & $0.084^{* * *}$ & $0.082^{* * *}$ & $0.087^{* * *}$ & 0.014 \\
& $(0.0227)$ & $(0.0227)$ & $(0.0229)$ & $(0.0276)$ & $(0.0217)$ \\
High-SES x Priming & -0.009 & -0.014 & -0.022 & -0.023 & -0.083 \\
& $(0.0656)$ & $(0.0656)$ & $(0.0660)$ & $(0.0661)$ & $(0.0519)$ \\
Priming x Predicted returns & & & & -0.184 & 0.332 \\
& & & & $(0.5790)$ & $(0.4540)$ \\
\hline p-value(High-SES x Priming $=0)$ & 0.894 & 0.830 & 0.743 & 0.729 & 0.112 \\
\hline Controls & No & Yes & Yes & Yes & Yes \\
Predicted returns (cubic polynomial) & No & No & Yes & Yes & Yes \\
\hline Control group mean & 0.561 & 0.561 & 0.561 & 0.561 & 0.171 \\
Observations & 2103 & 2103 & 2071 & 2071 & 2071 \\
R-Squared & 0.007 & 0.014 & 0.017 & 0.017 & 0.014 \\
\hline
\end{tabular}

Notes: All columns are OLS regressions with very worried or desperate as the dependent variable in first four columns and desperate as the dependent variable in the last column. Very worried or desperate $=1$ if the subject reported being very worried or desperate about paying household bills by the end of the month, and 0 otherwise. Desperate $=1$ if the subject reported being desperate about paying household bills by the end of the month, and 0 otherwise. High-SES $=1$ if the subject completed higher education, and 0 otherwise. Priming $=1$ if subject was primed about financial worries, and 0 otherwise. Child-specific predicted effects on graduation rates generated from Bettinger et al. (2020)'s experimental results, using machine learning techniques. Controls include student's race, age and gender, and their caregiver's race, age, income and schooling. Standard errors in parentheses. ${ }^{* * *} \mathrm{p}<0.01,{ }^{*} * \mathrm{p}<0.05,{ }^{*} \mathrm{p}<0.1$. 
Online Appendix E - Predicted Returns and Robustness Tests

An active literature in behavioral public economics deals with the challenge of evaluating whether decisions are optimal by constructing a "counterfactual normative decision-maker" based on survey data - taking as "optimal" the decisions made by fully informed subjects (possibly augmented by other features such as lack of self-control problems; see for instance Allcott, Lockwood and Taubinsky, 2019). Decisions that deviate from that "normative" pattern are interpreted as biased. This approach assumes that any unobserved preferences are conditionally independent of bias. In our setting, that would be equivalent to assuming that being informed about investment returns does not correlate with subject-specific returns - a strong assumption in face of complementarities between school and home environment (see Agostinelli, Saharkhiz and Wiswall, 2020).

In contrast, our approach does not rely on such strong assumption. We observe predicted returns of the program for all study participants, thanks to the combination of the experiment in Bettinger et al. (2020) with the machine learning techniques described in Appendix B. As such, we can estimate treatment effects controlling flexibly for predicted returns, and document that financial worries reopen the SES investment gap even for parents with the highest predicted returns - those for whom it is much easier to claim that the investing is optimal, given the large expected earnings differential of graduating high-school in Brazil (see Appendix B.B2.

Table E1 shows that our results are robust to controlling flexibly for an alternative version of predicted returns, computed within a different sub-sample of parents in Bettinger et al. (2020) (see Appendix B.B3). Column (1) shows that the prior experience increases the probability of investment by 20.5 p.p., whereas priming financial worries reduces the likelihood by 13.4 p.p. (significant at $5 \%$ level) among those parents. Columns (2) and (3) report that, among those with prior experience, priming financial worries only impacts low-SES parents (significant at 5\% level); we reject the hypothesis that the impact of priming is identical for low-SES and high-SES parents at 10\% significance level. Column (4) shows that the results are robust to allowing priming effects to vary with this alternative version of predicted returns. Column (5) of the table estimates the impact of informing parents about the program's effects on the probability of investing in it. Among those with prior experience with the SMS program, information about the impact reduced the likelihood of investing by 17.7 p.p. (significant at $1 \%$ level). Column (6) reports the results of the full interaction model; we fail to reject the hypothesis that the effect of the priming and that of information are statistically identical $(\mathrm{p}=0.463)$.

Table E2 shows that the effect size of financial worries on the likelihood of investment among those with prior experience with the program not only remains very large as we restrict attention to parents above the 25th, 50th and 75th percentiles of predicted returns, but also, remains largely stable and precisely estimated - despite progressively smaller sample sizes. 
Table E1-Effects of prior experience and priming on willingness to invest, alternative predicted returns of the SMS program

\begin{tabular}{|c|c|c|c|c|c|c|}
\hline & \multicolumn{4}{|c|}{ Information $=0$} & \multirow{2}{*}{$\begin{array}{c}\text { Priming }=0 \\
(5)\end{array}$} & \multirow{2}{*}{$\begin{array}{c}\text { Full Sample } \\
\qquad \begin{array}{l}\text { (6) }\end{array}\end{array}$} \\
\hline & $\begin{array}{l}\text { Overall } \\
\text { (1) }\end{array}$ & $\begin{array}{c}\text { Low-SES } \\
(2)\end{array}$ & $\begin{array}{l}\text { High-SES } \\
\text { (3) }\end{array}$ & $\begin{array}{c}\text { Overall } \\
(4)\end{array}$ & & \\
\hline Prior experience & $\begin{array}{c}0.205^{* * *} \\
(0.0429)\end{array}$ & $\begin{array}{c}0.217^{* * *} \\
(0.0456)\end{array}$ & $\begin{array}{c}0.050 \\
(0.1317)\end{array}$ & $\begin{array}{c}0.205^{* * *} \\
(0.0430)\end{array}$ & $\begin{array}{c}0.209 * * * \\
(0.0425)\end{array}$ & $\begin{array}{c}0.208^{* * *} \\
(0.0424)\end{array}$ \\
\hline Priming $\mathrm{x}$ Prior experience & $\begin{array}{c}-0.134^{* *} \\
(0.0609)\end{array}$ & $\begin{array}{c}-0.161^{* *} \\
(0.0650)\end{array}$ & $\begin{array}{c}0.158 \\
(0.1828)\end{array}$ & $\begin{array}{l}-0.123^{*} \\
(0.0635)\end{array}$ & & $\begin{array}{c}-0.135^{* *} \\
(0.0603)\end{array}$ \\
\hline Priming & $\begin{array}{c}0.056 \\
(0.0461)\end{array}$ & $\begin{array}{c}0.071 \\
(0.0491)\end{array}$ & $\begin{array}{c}-0.137 \\
(0.1415)\end{array}$ & $\begin{array}{c}0.047 \\
(0.0492)\end{array}$ & & $\begin{array}{c}0.056 \\
(0.0456)\end{array}$ \\
\hline Priming $\mathrm{x}$ Prior experience $\mathrm{x}$ Predicted returns & & & & $\begin{array}{c}-0.944 \\
(1.5756)\end{array}$ & & \\
\hline Priming $x$ Predicted returns & & & & $\begin{array}{c}0.739 \\
(1.4438)\end{array}$ & & \\
\hline Information $\mathrm{x}$ Prior experience & & & & & $\begin{array}{c}-0.177^{* * *} \\
(0.0616)\end{array}$ & $\begin{array}{c}-0.180^{* * *} \\
(0.0616)\end{array}$ \\
\hline Information & & & & & $\begin{array}{c}0.052 \\
(0.0479)\end{array}$ & $\begin{array}{c}0.051 \\
(0.0478)\end{array}$ \\
\hline Priming $\mathrm{x}$ Prior experience $\mathrm{x}$ Information & & & & & & $\begin{array}{l}0.217^{* *} \\
(0.0872)\end{array}$ \\
\hline Priming $\mathrm{x}$ Information & & & & & & $\begin{array}{c}-0.099 \\
(0.0666)\end{array}$ \\
\hline $\begin{array}{l}\text { p-value (Info x Prior exp. [low-SES }=\text { high-SES }]) \\
\text { p-value([Info x Prior exp.] }=[\text { Priming x Prior exp.]) }\end{array}$ & & & & & & 0.463 \\
\hline Controls & Yes & Yes & Yes & Yes & Yes & Yes \\
\hline Predicted returns (cubic polynomial) & Yes & Yes & Yes & Yes & Yes & Yes \\
\hline Control group mean & 0.329 & 0.310 & 0.481 & 0.329 & 0.329 & 0.329 \\
\hline Observations & 1080 & 938 & 142 & 1080 & 1059 & 2082 \\
\hline R-Squared & 0.026 & 0.030 & 0.064 & 0.027 & 0.038 & 0.023 \\
\hline
\end{tabular}

Notes: All columns are OLS regressions with dependent variable $=1$ if the subject chose to exchange $\mathrm{R} \$ 10$ in airtime credit for 6 months of the SMS program, and 0 otherwise. Prior experience $=1$ if the subject was randomly assigned to the SMS program in the previous RCT, and 0 otherwise. Priming $=1$ if subject was primed about financial worries, and 0 otherwise. Child-specific predicted effects on graduation rates generated from Bettinger et al. (2020)'s experimental results, using machine learning techniques. Controls include student's race, age and gender, and their caregiver's race, age, income and schooling. Standard errors in parentheses. $* * *$ $\mathrm{p}<0.01,{ }^{* *} \mathrm{p}<0.05,{ }^{*} \mathrm{p}<0.1$. 
Table E2-Effects of prior experience and priming on willingness to invest, by predicted returns of the SMS program

\begin{tabular}{lcccc}
\hline \hline & \multicolumn{4}{c}{ Information $=0$} \\
\cline { 2 - 5 } & $\mathrm{r}>0 \%$ & $\mathrm{r}>0.04 \%$ & $\mathrm{r}>1.1 \%$ & $\mathrm{r}>2.8 \%$ \\
& $(1)$ & $(\mathrm{p} 25)$ & $(\mathrm{p} 50)$ & $(\mathrm{p} 75)$ \\
& $0.176^{* * *}$ & $0.219^{* * *}$ & $0.286^{* * * *}$ & $0.350^{* * *}$ \\
\hline Prior experience & $(0.0422)$ & $(0.0482)$ & $(0.0588)$ & $(0.0822)$ \\
Priming x Prior experience & $-0.112^{*}$ & $-0.150^{* *}$ & $-0.219^{* * *}$ & $-0.294^{* *}$ \\
& $(0.0601)$ & $(0.0684)$ & $(0.0836)$ & $(0.1163)$ \\
\hline Controls & Yes & Yes & Yes & Yes \\
\hline Control group mean & 0.335 & 0.107 & 0.139 & 0.336 \\
Observations & 1106 & 854 & 569 & 294 \\
R-Squared & 0.020 & 0.029 & 0.050 & 0.083 \\
\hline
\end{tabular}

Notes: All columns are OLS regressions with dependent variable $=1$ if the subject chose to exchange $\mathrm{R} \$ 10$ in airtime credit for 6 months of the SMS program, and 0 otherwise. Prior experience $=1$ if the subject was randomly assigned to the SMS program in the previous RCT, and 0 otherwise. Priming $=1$ if subject was primed about financial worries, and 0 otherwise. Child-specific predicted effects on graduation rates $(r)$ generated from Bettinger et al. (2020)'s experimental results, using machine learning techniques. Controls include student's race, age and gender, and their caregiver's race, age, income and schooling. Standard errors in parentheses. $* * * \mathrm{p}<0.01, * * \mathrm{p}<0.05, * \mathrm{p}<0.1$. 


\section{Online Appendix F - Performance in Incentivized Cognitive Tests}

Our phone survey includes incentivized cognitive tests, following Lichand and Mani (2020). The cognitive outcomes we measure comprise tasks aimed at assessing attention, together with working memory and impulse control (so called brain's executive functions; Diamond, 2013). We measure attention and working memory through digit span tests, in which subjects must remember as many digits as they can from the strings they hear (the more digits accurately recalled, the higher the score). We measure attention and impulse control through Stroop tests, in which subjects must answer the number of times they heard a particular digit repeated in a sequence. While it is tempting to press the digit that one has just heard repeated multiple times, the correct answer is never the digit itself. See Appendix A for the full script of the cognitive tests in our phone survey.

For each cognitive test $\mathrm{j}$, we estimate the following equation:

$$
Y_{i}^{j}=\alpha+\beta_{j} \operatorname{Priming}_{i}+\sum \gamma_{k} X_{k, i}+\varepsilon_{i}
$$

In equation $\mathrm{F} 1$, in the case of digit span, $Y_{i}^{j}$ is given by the share of accurately recalled digits, across all versions of the test; in the case of Stroop, $Y_{i}^{j}$ is given by the share of correctly identified number of repetitions, across all versions of the test; Priming $_{i}=1$ if caregiver $\mathrm{i}$ is primed about financial worries, and 0 otherwise; $X_{i}$ is a vector of student and family characteristics, and $\varepsilon_{i}$ is an error term.

Since we conduct a multiplicity of tests, estimating separate regressions for each outcome would substantially inflate the probability of false positives above stated significance levels. For this reason, we build summary measures for each set of outcomes and for cognitive load, following Kling, Liebman and Katz (2007). To do that, we first normalize all outcomes to z-scores. Second, we run seemingly unrelated regressions (SUR) to compute an effect size $\hat{\beta}$ for each summary measure, given by equation F2.

$$
\hat{\beta}=\frac{1}{K} \sum \frac{\hat{\beta}_{j}}{\hat{\sigma}_{c, j}}
$$

In equation $\mathrm{F} 2, \hat{\beta}_{j}$ are the point estimates obtained for ordinary least squares (OLS) regressions of $\mathrm{Y}^{j}$ on a particular treatment variable, $\hat{\sigma}_{c, j}$ is the variance of that outcome for the control group, and $K$ is the number of outcomes in that category. We use bootstrapping to obtain standard errors for $\hat{\beta}$.

In Lichand and Mani (2020), priming subjects about financial worries deteriorates cognitive performance on average, but effects are highly heterogeneous according to municipality's per capita income. Among the poorest municipalities, the priming strongly worsens performance in attention, memory and impulse control tests, whereas in richest municipalities (with per capita income levels close 
to that of São Paulo State), it actually generates a cognitive bonus: the opportunity for short-term gains actually significantly improves performance incentivizes cognitive tests. As such, we are interested in whether $\beta \geq 0$, consistent with poverty-induced reallocation of mental bandwidth.

Table F1 estimates the effect of the priming on cognitive outcomes. Column (1) regresses the summary measure on the priming indicator; column (2) adds students' and caregivers' characteristics and controls flexibly for predicted returns; column (3) adds the interaction of priming with an indicator of high socioeconomic status; and columns (4) and (5) turn to the components of the cognitive performance summary measure: digit span and Stroop, respectively.

Results confirm that, consistent with the mental bandwidth reallocation, experimentally poor subjects perform significantly better in those tests: the priming improves cognitive performance (measured by the summary measure) by over 0.08 standard deviation - about $1 / 3$ of the correlation between cognitive performance and college education in our sample. Effects are precisely estimated, statistically significant at the 5\% level (column 1) and are robust to controlling for students' and their caregivers' characteristics and child-specific predicted returns of the SMS program (column 2). Column (3) documents that effects are concentrated on low-SES parents (effects are smaller and no longer statistically significant for high-SES parents, $\mathrm{p}=0.627$ ). Last, columns (4) and (5) document that effects are not driven by any specific component of the summary measure; financial worries improve cognitive performance in face of small but immediate rewards in both Stroop and digit span tests (significant at the 10\% and 5\% levels, respectively). 
Table F1-Cognitive performance

\begin{tabular}{|c|c|c|c|c|c|}
\hline & \multicolumn{3}{|c|}{ Summary measure } & \multirow{2}{*}{$\begin{array}{c}\text { Digit span } \\
\text { (4) }\end{array}$} & \multirow{2}{*}{$\begin{array}{c}\text { Stroop } \\
(5)\end{array}$} \\
\hline & $(1)$ & $(2)$ & $(3)$ & & \\
\hline Priming & $\begin{array}{c}0.082^{* *} \\
(0.033)\end{array}$ & $\begin{array}{c}0.077^{* *} \\
(0.034)\end{array}$ & $\begin{array}{c}0.080^{* *} \\
(0.038)\end{array}$ & $\begin{array}{c}0.079^{*} \\
(0.0480)\end{array}$ & $\begin{array}{l}0.092^{* *} \\
(0.0454)\end{array}$ \\
\hline Priming x High-SES & & & $\begin{array}{l}-0.026 \\
(0.120)\end{array}$ & & \\
\hline High-SES & & & $\begin{array}{c}0.180^{* *} \\
(0.082)\end{array}$ & & \\
\hline $\mathrm{p}$-value $([$ Priming $]+[$ Priming $\times$ High-SES $]=0)$ & & & 0.627 & & \\
\hline Controls & No & Yes & Yes & Yes & Yes \\
\hline Predicted returns (cubic polynomial) & No & Yes & Yes & Yes & Yes \\
\hline Observations & 1729 & 1700 & 1700 & 1700 & 1933 \\
\hline R-Squared & 0.002 & 0.027 & 0.030 & 0.029 & 0.020 \\
\hline
\end{tabular}

Notes: Columns (1) to (3) are Seemingly Unrelated Regressions (SUR), with the summary measure of cognitive performance as dependent variable. Columns (4) and (5) are OLS regressions with the components of the summary measure as dependent variables (digit span and Stroop, respectively). Priming $=1$ if the subject was primed about financial worries, and 0 otherwise. High-SES $=1$ if the subject completed higher education, and 0 otherwise. Child-specific predicted effects on graduation rates generated from Bettinger et al. (2020)'s experimental results, using machine learning techniques. Controls include student's race, age and gender, and their caregiver's race, age, income and schooling. Standard errors in parentheses. ${ }^{* * *} \mathrm{p}<0.01,{ }^{* *} \mathrm{p}<0.05,{ }^{*} \mathrm{p}<0.1$. 


\section{Online Appendix G - Additional Figures}

This Appendix compiles additional figures. Figure G1 showcases the SES investment gap: high-SES parents are more likely to invest in the SMS program than low-SES parents across all levels of its predicted returns. Next, Figure G2 documents that prior experience with the SMS program increases willingness to invest - and, in fact, even increases demand's slope with respect to the program's predicted returns, relative to the control group. Last, Figures G3 and G4 show that both priming financial worries and informing parents about the (small) effects of the SMS program on attendance in math classes reduces their willingness to invest, relative to the control group. 
Figure G1. Investment decision by SES

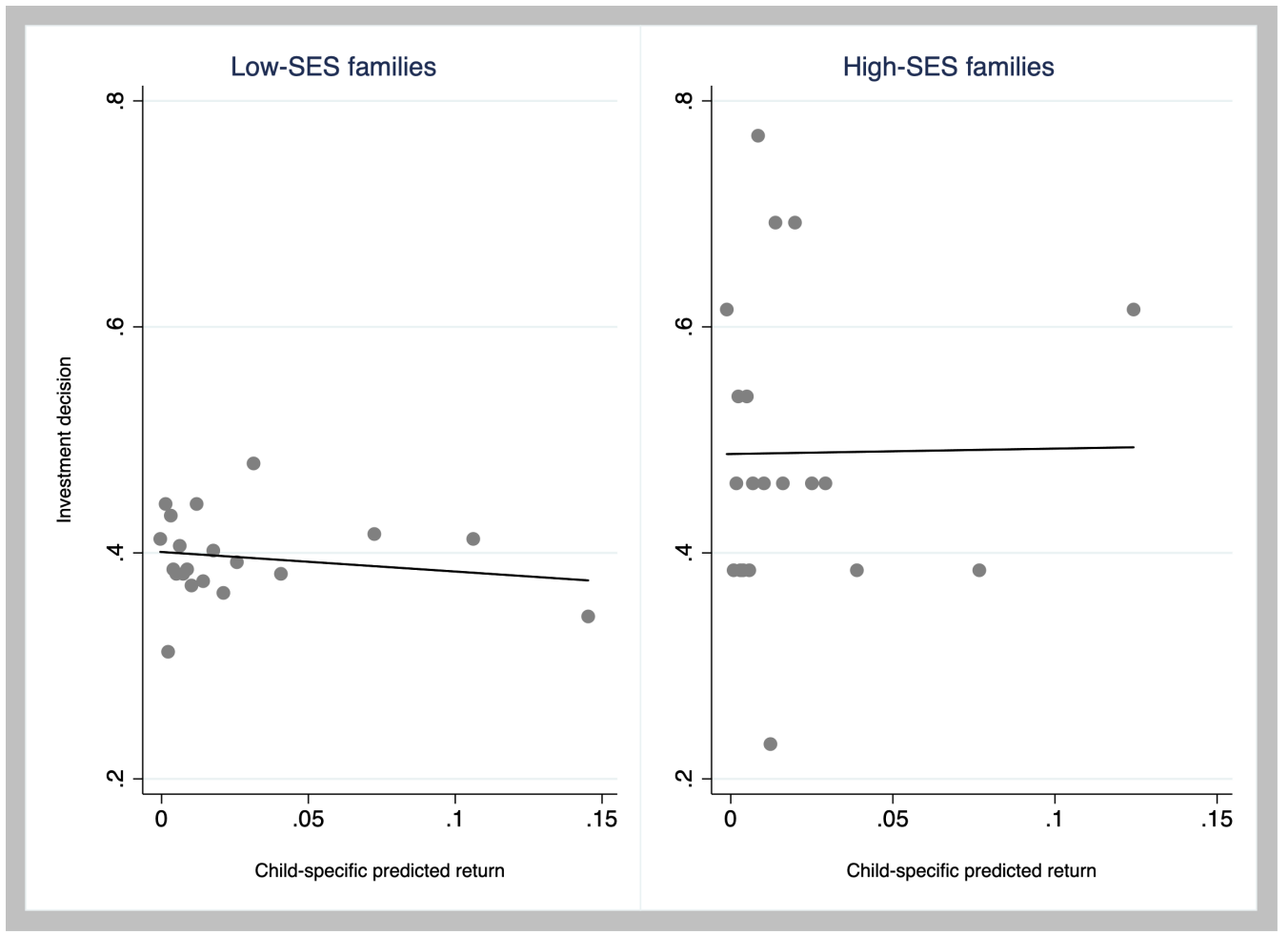

Notes: Binscatter plots of subjects' investment decisions as a function of child-specific predicted returns, separately for low-SES subjects (left panel) and high-SES ones (right panel). Investment $=1$ if the subject chose to exchange $\mathrm{R} \$$ 10 in airtime credit for 6 months of the SMS program and 0 otherwise. Child-specific predicted effects on graduation rates generated from Bettinger et al. (2020)'s experimental results, using machine learning techniques. 
Figure G2. Effects of prior experience

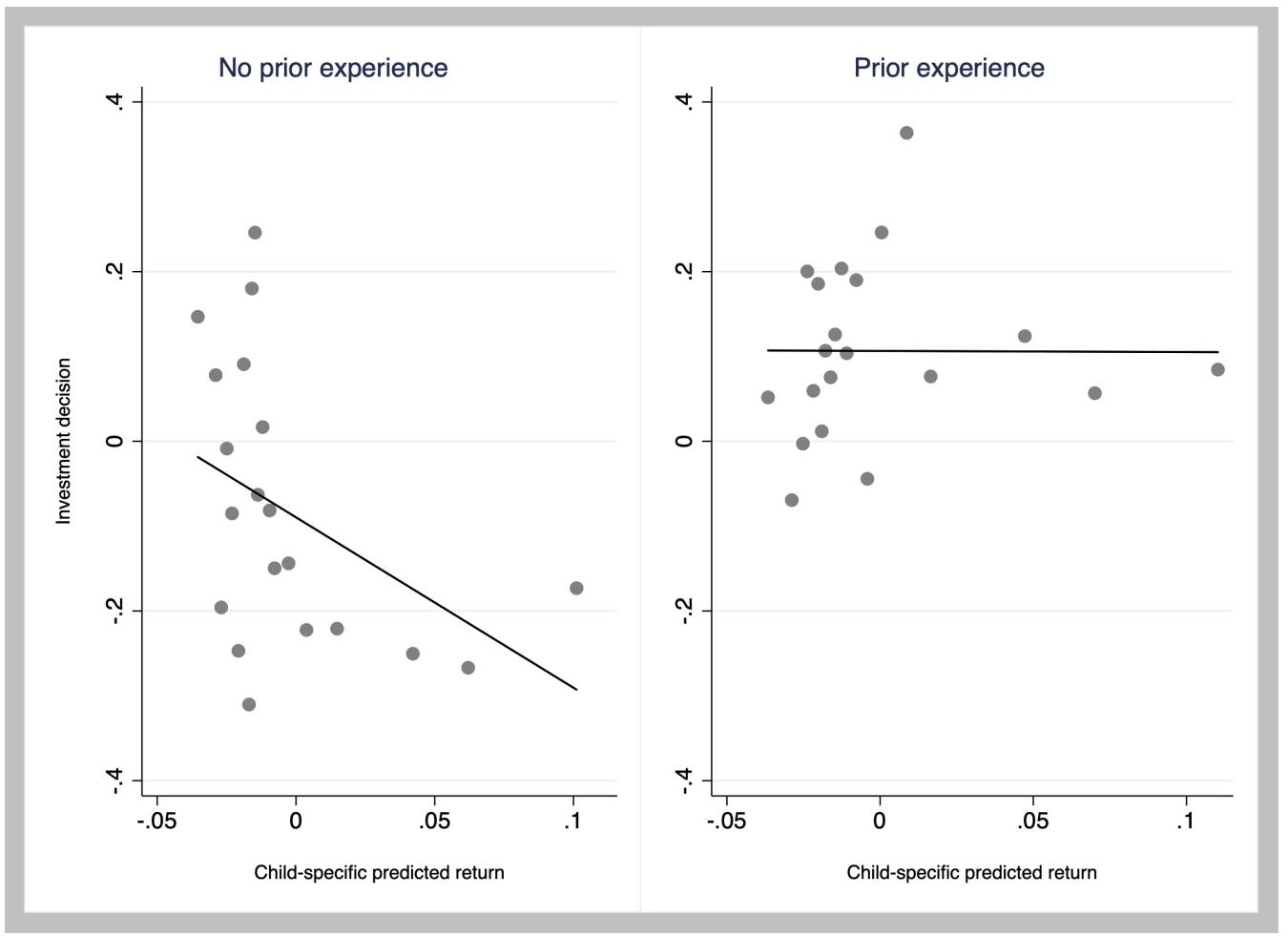

Notes: Binscatter plots of subjects' investment decisions as a function of child-specific predicted returns, separately for subjects with no prior experience with the SMS program (left panel) and those with prior experience (right panel). Prior experience $=1$ if the subject was randomly assigned to the SMS program in the previous RCT, and 0 otherwise. Investment $=1$ if the subject chose to exchange $\mathrm{R} \$ 10$ in airtime credit for 6 months of the SMS program and 0 otherwise. Child-specific predicted effects on graduation rates generated from Bettinger et al. (2020)'s experimental results, using machine learning techniques. Both variables residualized with respect to student's race, age and gender, and their caregiver's race, age, income and schooling. 
Figure G3. Effects of financial worries

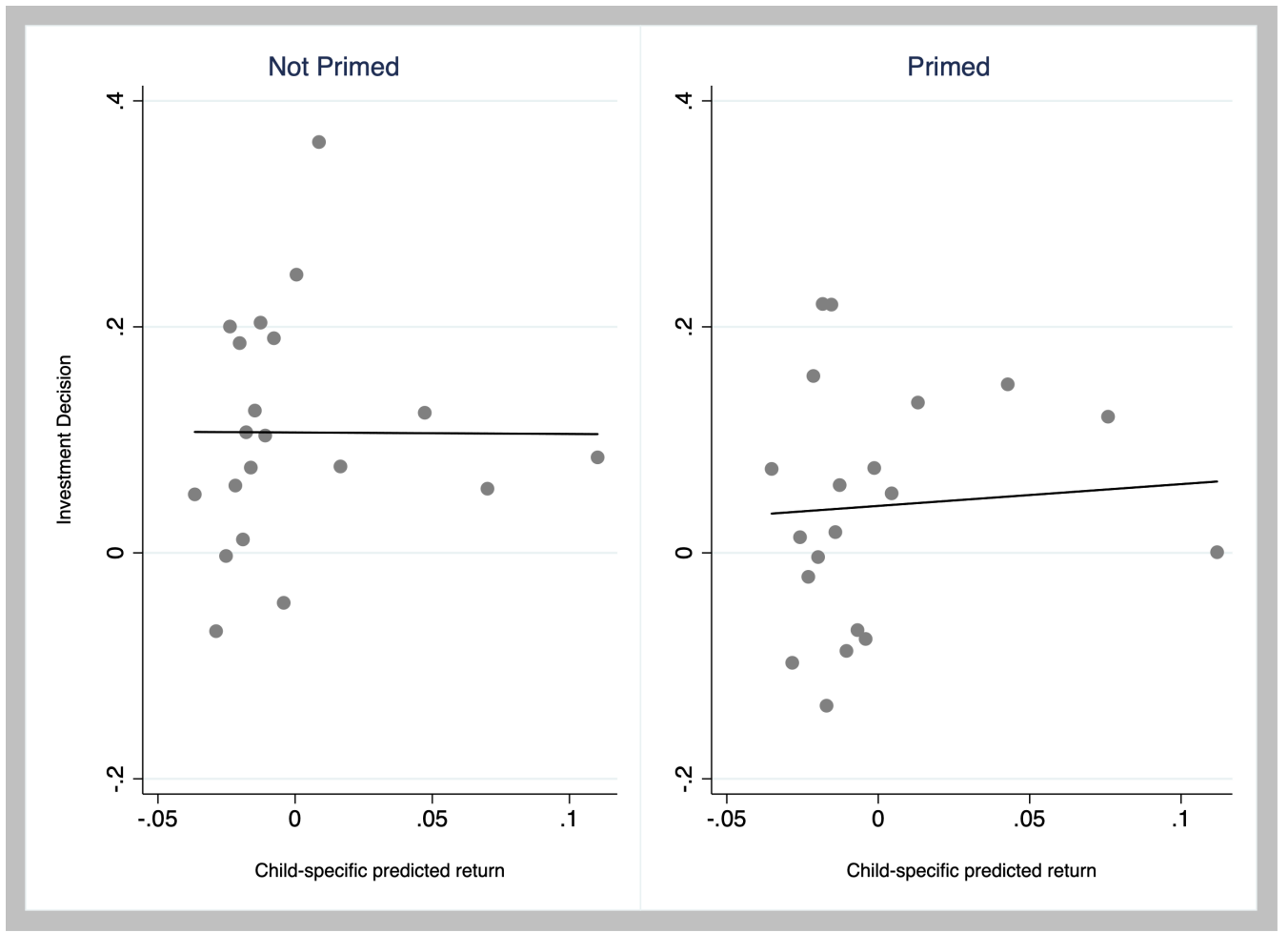

Notes: Binscatter plots of subjects' investment decisions as a function of child-specific predicted returns, separately for subjects not primed about financial worries (left panel) and those primed (right panel). Priming $=1$ if subject was in the treatment group of the survey experiment, and 0 otherwise. Investment $=1$ if the subject chose to exchange $\mathrm{R} \$ 10$ in airtime credit for 6 months of the SMS program and 0 otherwise. Child-specific predicted effects on graduation rates generated from Bettinger et al. (2020)'s experimental results, using machine learning techniques. Both variables residualized with respect to student's race, age and gender, and their caregiver's race, age, income and schooling. 
Figure G4. Effects of informing parents about child-specific effects on attendance

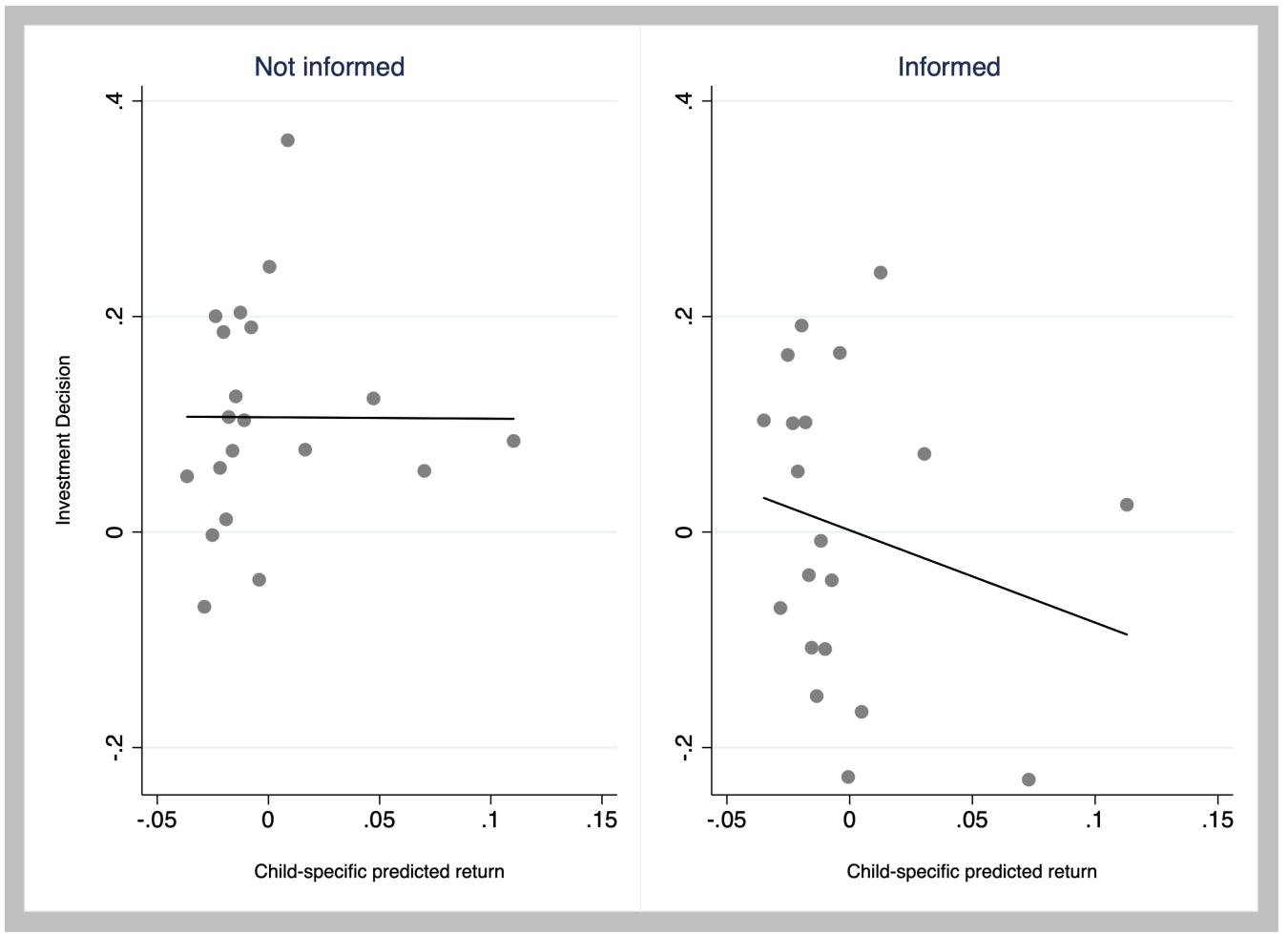

Notes: Binscatter plots of subjects' investment decisions as a function of child-specific predicted returns, separately for subjects not informed about the effects of the program (left panel) and those informed (right panel). Information $=1$ if the subject was informed over text message about child-specific predicted effects of the SMS program on attendance, and 0 otherwise. Investment $=1$ if the subject chose to exchange $\mathrm{R} \$ 10$ in airtime credit for 6 months of the SMS program and 0 otherwise. Child-specific predicted effects on graduation rates generated from Bettinger et al. (2020)'s experimental results, using machine learning techniques. Both variables residualized with respect to student's race, age and gender, and their caregiver's race, age, income and schooling. 


\section{Online Appendix H - Early Version of Pre-Analysis Plan}

Only an early version of the pre-analysis plan was registered at the AEA Social Science Registry as AEARCTR-0001380, on June 26, 2016. It is presented in full in subsection H.H2, Before that, subsection H.H1 highlights the elements of the analyses that deviate from what had been specified in that early pre-analysis plan.

\section{H1. Deviations from early pre-analysis plan}

We had pre-registered the experimental design at the same time as the one in Bettinger et al. (2020), as we thought at the time the two would be conducted simultaneously. As such, an important distinction from our analysis to that early version of the pre-analysis plan is that the latter did not set out to investigate demand for the SMS program as a function of predicted returns (since those would not have been available at that time).

Over the course of 2016, when the prior experience experiment was taking place, we only piloted the survey and information experiments analyzed in this paper, and concluded several changes were in order before the experiments could be rolled out in 2017. Besides the issue of predicted returns - crucial for establishing whether differences in investment patterns induced by the priming are indeed inefficient -, we modified these experiments in the following ways.

When it comes to the survey experiment, the early version of the pre-analysis envisioned different versions of the priming and control messages at the beginning of the phone call. Two arms were linked to small vs. large shocks related to education expenses (the ones that were ultimately kept through the main experiment). There was an additional arm in which the priming was linked to a large shock unrelated to education, to assess whether it mattered that the shock and the investment were both within the same domain. The problem is that the shock we chose to use - a thought experiment in which the household's fridge had to be repaired - failed the manipulation test: financial worries did not increase nearly as much in response to that priming in the pilot. For this reason, we removed that variation from the main experiment. We also piloted a different version of the control condition: a thought experiment in which there was a lasting unanticipated cut in the household's water supply, a large shock unrelated to financial worries. Using that arm as a control condition seemed to yield similar results as using the small shock in the pilot; for that reason, we kept only the latter in the main experiment to maximize statistical power of the comparison and to keep it in line with the typical approach in prior studies.

In the information experiment, we had envisioned that it would be also included as part of the phone survey, by framing the investment in alternative ways: in the control condition, we would merely state that the SMS program is "good for your child", while in the treatment condition, that it has the potential to "increase future wages". The pilot suggested, however, that mentioning wages just 
before the investment decision was also priming subjects about financial worries, conflating the two experiments. That led us to switch to implementing the information experiment through text messages, 2 days before the phone survey. What is more, since in 2017 we could compute child-specific predicted returns, we used those predictions to inform parents in the treatment group, while for the control group we stated how many parents participated in the program in the previous year.

Last, we did not pre-specify that we would use college education to contrast high- vs. low-SES parents in our experiments. In 2016, it was hard to anticipate whether we would be able to contact enough high-SES parents in order to draw those comparisons with sufficient statistical power. Having said that, our results for the effects of the priming on investment decisions hold even on average, and we use our SES proxy to shed additional light on the psychological mechanisms at play.

\section{H2. Early pre-analysis plan}

\section{BACKGROUND}

A growing body of evidence suggests that parents play a crucial role in shaping their children's behavior and performance in school (Houtenville and Conway, 2008; Nye, Turner and Schwartz, 2006; Barnard, 2004; Fan and Chen, 2001). In fact, differences in parental inputs are viewed as an important cause of intergenerational inequality (Becker and Tomes, 1979). This paper studies how poverty may impose a psychological tax on parenting, generating a poverty trap even on the absence of binding credit constraints for educational investments. There is reason to think that this may be the case. While low-cost interventions have been shown to significantly increase parental engagement and students' outcomes (Kraft and Rogers, 2015; York and Loeb, 2014), such interventions tend to have significantly lower or no effects among minorities (black families in Chicago, in Fryer et al. 2015, and Chinese families in San Francisco, in York and Loeb, 2014). One hypothesis for why that might be comes from the cognitive load/mental bandwidth theory Mullainathan and Shafir (2013): such parents might have less attention, memory and impulse control available to parenting, because poverty generates cognitive load (Mani et al., 2013, Lichand and Mani, 2020).

To test whether poor parents have a lower propensity to invest in their children due to cognitive load, we resort to survey experiments, priming some parents but not others - about money, and then presenting them with the opportunity to undertake a costly educational investment in their child. The hypothesis of interest is whether those who are primed undertake such investment to a lesser extent.

Such empirical strategy raises three main concerns. First, if there is an effect, how do we know that it is driven by cognitive load, rather than just by a negative mental state following the arrival of bad news (Lerner et al., 2015)? Second, the 
fact that the investment is costly may confound the effect of cognitive load with that of credit constraints. And third, if the decision is hypothetical, then it is hard to get a sense of whether it matters quantitatively.

To deal with the first concern, we randomly assign sub-samples of the subject pool to other sources of negative news: either a monetary shock of much lower magnitude, or a non-monetary shock. Moreover, we also try to delve more deeply into the mechanism, by varying the source of the large monetary shocks - either related or unrelated to educational expenses -, to address the possibility of mental accounting (Thaler, 1999).

To deal with the second concern, we create a decision that involves opportunity costs, but which does not require cash on hand. Specifically, we offer parents the choice between a free educational product for a longer period, or the same product for a shorter period coupled with an immediate top up in airtime credit. The idea is that if those who are primed about money choose the short-length plan, it cannot be because they were credit constrained to choose the longer-length one.

To deal with the third concern, we present parents with a decision about a real product. We offer enrollment in an SMS campaign that delivers content to support parenting, an increasingly popular intervention to foster parental engagement (York and Loeb, 2014), for either 2.5 or 5 months of the school year. Beyond having real consequences, we can actually measure the impact of parents' decisions on their children's education outcomes - attendance, grades and drop-out rates -. The psychological impact of poverty on those outcomes is then estimated by using priming status as an instrumental variable for parents' decisions between shorter- or longer-length plans.

Last, we also offer parents a savings technology, presenting all subjects with the trade-off between receiving an immediate 5-dollar airtime credit top-up for answering the survey, or a 10-dollar top-up one month later instead. Estimating the effects of the priming on subjects' discount rate provides us yet another way to benchmark priming's effect size on that educational decision.

While the cognitive load/mental bandwidth theory predicts that poverty might impose a psychological tax on poor parents' cognition, it also predicts that the poor should perform relatively better in tasks framed in monetary terms (Shah, Shafir and Mullainathan, 2015, Lichand and Mani, 2020). By precisely exploiting this mechanism, interventions to foster parental engagement among the poor might be improved by framing communication in monetary terms.

This paper also tests this hypothesis, by cross-randomizing how the educational investment is presented for parents (framed as either "good for your child" or "with potential to increase future wages"). We test whether the monetary framing increases uptake of the longer-length plan, particularly for the subjects primed about money. 


\section{INTERVENTION AND SAMPLE}

Survey experiments are randomly assigned at student levels, within a sample of 60 Brazilian public schools, in order to estimate the psychological impacts of poverty on educational investments. Using phone surveys, at the beginning of each call we randomly assign parents to one out of four possible questions, asking subjects to think about the consequences of: (i) a small monetary shock (a USD 10 unanticipated expenditure with a broken fridge; the control condition), (ii) a large monetary shock unrelated to education (a USD 100 unanticipated expenditure with a broken fridge), (iii) a large monetary shock related to education (a USD 100 unanticipated expenditure with school uniform and materials), and (iv) a large non-monetary shock (a unanticipated 7 -week stop in water supply; the placebo condition). Following that, we offer parents the opportunity to undertake an educational investment, by choosing the length during which they will be enrolled in an SMS campaign that delivers content to support parenting (at no cost). Subjects must decide between 2.5-months enrollment coupled with an immediate airtime credit top-up of 5 dollars, or 5 -months enrollment with no top-up. We cross-randomize how the educational investment is presented for parents (framed as either "good for your child" or "with potential to increase future wages").

Table - Research Design

Table H1-Research Design

\begin{tabular}{lcc}
\hline \hline & Non-monetary framing & Monetary framing \\
\hline $\begin{array}{l}\text { Small monetary stock } \\
\begin{array}{l}\text { Large monetary shock unrelated to } \\
\text { education }\end{array}\end{array}$ & 625 parents & 625 parents \\
$\begin{array}{l}\text { Large monetary shock related to } \\
\text { education }\end{array}$ & 625 parents & 625 parents \\
Large non-monetary shock & 625 parents & 625 parents \\
\hline
\end{tabular}

\section{Outcomes}

The key outcome of interest is parents' decision to undertake or not the educational investment, which we will collect through the same IVR at which we run the survey experiments. At the end of the intervention, the São Paulo Secretariat of Education will provide data on student attendance and grades in 2016 (per quarter), and enrollment in 2017. Moreover, the Secretariat implements annually a standardized test to all schools in the state of São Paulo, SARESP (System of 
School Performance Evaluation of the State of São Paulo). All students in grades 1st, 3rd, 5th, 7th, 9th of primary school and the final year of high school are tested on their knowledge of Mathematics and Portuguese.

Timeline \& Milestones

Table H2-Timeline and Milestones

\begin{tabular}{|c|c|c|c|}
\hline$\#$ & Milestone & Target Start Date & Target End Date \\
\hline 1. & $\begin{array}{l}\text { Meeting with the Regional Board of Educa- } \\
\text { tion Directors and the São Paulo Secretariat } \\
\text { of Education to explain the project }\end{array}$ & Apr-14 & Apr-14 \\
\hline 2. & $\begin{array}{l}\text { Regional Board of Education Directors meet } \\
\text { with their schools principals to explain the } \\
\text { project }\end{array}$ & Apr-18 & Apr-27 \\
\hline 3. & $\begin{array}{l}\text { Schools register to participate in the program } \\
\text { (trough an online form) }\end{array}$ & Apr-18 & Apr-27 \\
\hline 4. & $\begin{array}{l}\text { Meeting with Education Directors and school } \\
\text { principals in each of the } 5 \text { Regional Board of } \\
\text { Education head office to explain the project } \\
\text { and distribute the enrollment material }\end{array}$ & May-9 & May-17 \\
\hline 5. & $\begin{array}{l}\text { Schools organize meeting with parents to ex- } \\
\text { plain the project and obtain their cellphone } \\
\text { and consent }\end{array}$ & May-10 & May-30 \\
\hline 6. & $\begin{array}{l}\text { Teacher uploads parental enrollment informa- } \\
\text { tion through secure website }\end{array}$ & May-10 & June-2 \\
\hline 7. & Randomization & June-3 & June-5 \\
\hline 9. & Baseline phone survey implementation & June-6 & June-13 \\
\hline 10. & SMS content and nudges begin & June-14 & - \\
\hline 11. & End line phone surveys implementation & Dec-12 & Dec-20 \\
\hline 12. & SMS content and nudges end & Dec-20 & - \\
\hline 13. & Impact Evaluation & Jan-30 & Mar-31 \\
\hline
\end{tabular}

